\title{
Sexual and reproductive health needs of adolescents living with HIV in Kenya
}

\author{
Harriet Birungi \\ Population Council \\ Francis Obare \\ Population Council \\ Jane Harriet Namwebya \\ Ibrahim Mohammed
}

Margaret Gitau

See next page for additional authors

Follow this and additional works at: https://knowledgecommons.popcouncil.org/departments_sbsr-rh

Part of the Demography, Population, and Ecology Commons, Family, Life Course, and Society Commons, International Public Health Commons, and the Medicine and Health Commons How does access to this work benefit you? Let us know!

\section{Recommended Citation}

Birungi, Harriet, Francis Obare, Jane Harriet Namwebya, Ibrahim Mohammed, Margaret Gitau, and Margaret Makumi. 2011. "Sexual and reproductive health needs of adolescents living with HIV in Kenya," APHIA II Operations Research Project in Kenya Report. Nairobi: Population Council. 


\section{Authors}

Harriet Birungi, Francis Obare, Jane Harriet Namwebya, Ibrahim Mohammed, Margaret Gitau, and Margaret Makumi 


\section{Sexual and reproductive health needs of adolescents living with HIV in Kenya}
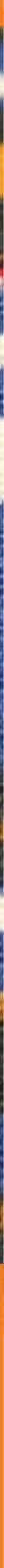


\title{
Sexual and reproductive health needs of adolescents living with HIV in Kenya
}

\author{
APHIA II Operations Research, Population Council \\ Harriet Birungi, Francis Obare
}

\begin{abstract}
APHIA II Rift Valley and Coast, Family Health International Jane Harriet Namwebya
\end{abstract}

\begin{abstract}
National AIDS and STI Control Programme (NASCOP)
\end{abstract} Ibrahim Mohammed, Margaret Gitau

\section{APHIA II Nairobi and Central, Pathfinder International} Margaret Makumi

February 2011 


\section{Acknowledgements}

This study is one of the APHIA II Operations Research (OR) projects in Kenya. The APHIA II OR project is funded by the USAID/Kenya Mission through cooperative agreement 623-A-00-09-0000100 between the Mission and Population Council. The study was a result of collaboration between Population Council, APHIA II Rift Valley and Coast (Family Health International, FHI), the National AIDS and STI Control Programme (NASCOP), and APHIA II Nairobi and Central (Pathfinder International).

The project received technical and logistical support from Ruth Odhiambo, Deputy Director, APHIA II Rift Valley; Gordon Nyanjom, Deputy Director, APHIA II Coast; and Maryanne Pribila, FHI- Nairobi. Other APHIA II staff members who played pivotal roles in ensuring the successful implementation of the study are Irene Muteti, Kenneth Alumasa, Christine Nyabundi, and Edward Yano (APHIA II Rift Valley); Lorina Kagosha, Roselyn Were, Fenny Mwamuye, Margaret Obwoge, and Caesar Ngule (APHIA II Coast). We are also grateful to the management of the HIV/AIDS treatment, care and support programs in Rift Valley and Coast provinces that granted the research team the permission to access their clients. Several service providers/ counselors, community health workers, and social workers contributed immensely toward the identification and mobilization of study participants.

We further acknowledge the invaluable cooperation received from our informants including service providers/ counselors for key informant interviews and young people living with HIV; they voluntarily provided the information for the study. The project would not have been successfully completed without the dedicated team of researchers including the two team leaders: Sheila Bayley and Salome Nyoike; the research assistants: Christabell Hoka, Keith Nyakundi, Winnie Kiarie, Gary James, Mohammed Aman, Caleb Leisene, Ismail Abdulaziz, Rehema Aida, Stacy Wayua, and Moses Odhiambo; the qualitative research team: Irene Namai, Edna Nduku, Nkeonyere Ezeh, and Elise Russell; as well as the translator for the survey tools, Naomi Moraa.

Winnie Osulah of the Population Council provided invaluable administrative support for the study while Erick Oweya, also of Population Council, programmed the Personal Data Assistants (PDAs).

The Institutional Review Board (IRB) of the Population Council, the Ethics Review Committee of the Kenya Medical Research Institute (KEMRI), and the Kenya National Council of Science and Technology (KNCST) granted ethical and research clearance for the study. Permission to access the comprehensive care centers (CCCs) within the Ministry of Health facilities was obtained from the National AIDS and STI Control Programme (NASCOP).

USAID IAPHIAII FROM THE AMERICAN PEOPLE OR Project in Kenya
This publication has been made possible with the generous support of the American people through USAID/Kenya, under the APHIA II Operations Research Project, a cooperative agreement No. 623-A-00-09-00001-00 between the Kenya Mission and the Population Council. The opinions expressed herein are those of the authors and do not necessarily reflect the views of USAID.

Suggested Citation: Birungi H., Obare F., Namwebya H. J., Mohammed M., Gitau, M., Makumi M., (2011) Sexual and reproductive health needs of adolescents living with HIV in Kenya; APHIA II OR Project in Kenya/ Population Council: Nairobi, Kenya.

(C) 2011, The Population Council, One Dag Hammarskjold Plaza New York, New York, 10017, www.popcouncil.org. The document may be freely reviewed, abstracted, reproduced or translated, in part or in whole, but not for sale nor use in conjunction with commercial purposes. 


\section{Contents}

Acknowledgements....................................... ii

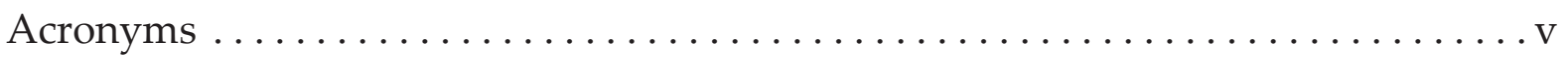

Executive summary $\ldots \ldots \ldots \ldots \ldots \ldots \ldots \ldots \ldots \ldots \ldots \ldots \ldots \ldots \ldots \ldots \ldots$

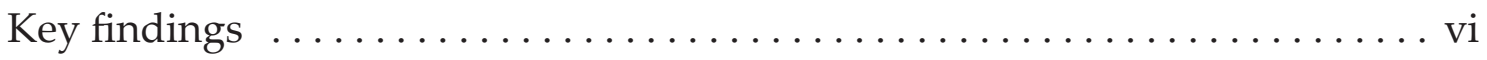

Programmatic implications $\ldots \ldots \ldots \ldots \ldots \ldots \ldots \ldots \ldots \ldots \ldots \ldots$ viii

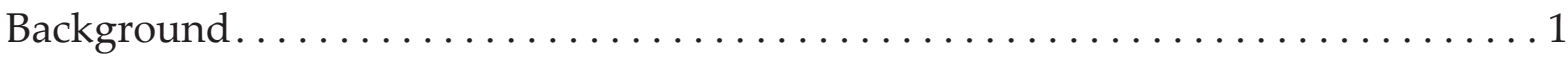

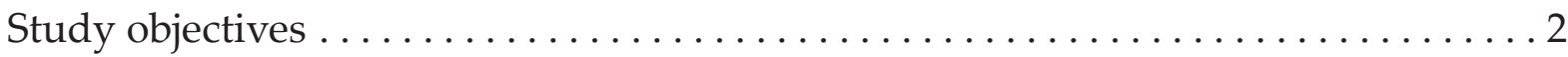

Methodology............................................. 2

Characteristics of adolescents living with HIV $\ldots \ldots \ldots \ldots \ldots \ldots \ldots \ldots \ldots$

Service provision, information and support $\ldots \ldots \ldots \ldots \ldots \ldots \ldots \ldots \ldots \ldots$

Dating and relationships................................... 9

Sexual desires and behavior.................................. 11

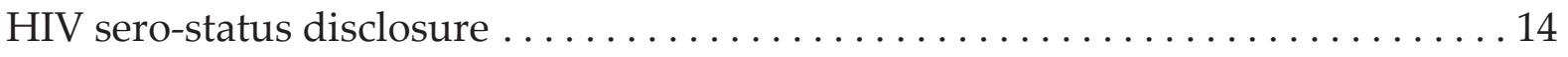

Knowledge of preventive and contraceptive methods................. 16

Use and sources of contraceptive methods . . . . . . . . . . . . . . . . . 17

Pregnancy and childbearing experiences and intentions................. 19

Pregnancy outcomes and use of health services ....................... 19

Experiences of violence and self-esteem. ........................ 22

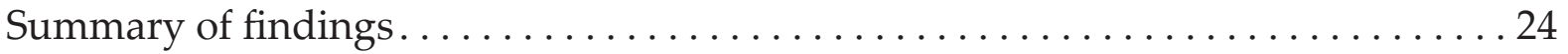

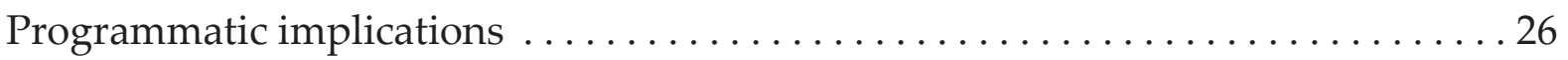

References ............................................ 29 


\section{List of tables}

Table 1: Distribution of survey participants by background characteristics . . . . . 4

Table 2: Percentage of respondents who ever talked with service providers and parents/guardians about sexual and reproductive health issues . . . . 7

Table 3: Distribution of respondents by frequency of feelings of discrimination. . . 8

Table 4: Distribution of respondents by experiences with relationships

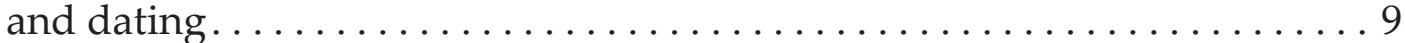

Table 5: Distribution of respondents by sexual desires and behavior $\ldots \ldots \ldots \ldots 12$

Table 6: Distribution of respondents by HIV sero-status disclosure . . . . . . . . . 15

Table 7: Distribution of respondents by knowledge and awareness of preventive/ contraceptive methods. .................. 16

Table 8: Distribution of respondents by use and source of contraceptive methods....................................... 17

Table 9: Distribution of respondents by pregnancy and childbearing experiences and intentions. . . . . . . . . . . . . . . . . . . . . . 19

Table 10: Distribution of pregnancies by outcomes and use of maternal and child health services according to study site . . . . . . . . . . 21

Table 11: Distribution of respondents by experiences of violence $\ldots \ldots \ldots \ldots \ldots 23$

Table 12: Percent distribution of respondents who are worried about

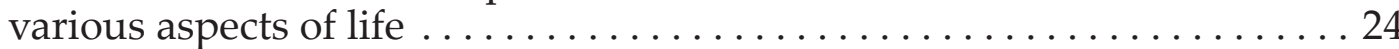

\section{List of figures}

Figure 1: Distribution of respondents not currently attending school by the major

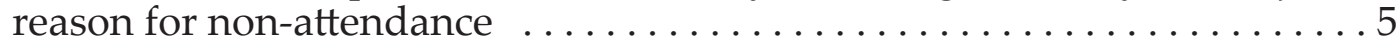

Figure 2: Distribution of respondents by the level of education and by whether they are in or out of school $\ldots \ldots \ldots \ldots \ldots \ldots \ldots \ldots \ldots \ldots \ldots \ldots \ldots \ldots \ldots \ldots \ldots$

Figure 3: Distribution of respondents by preferred choice of boyfriend/girlfriend/ partner . . . . . . . . . . . . . . . . 11

Figure 4: Distribution of respondents who have never had sex by intentions of

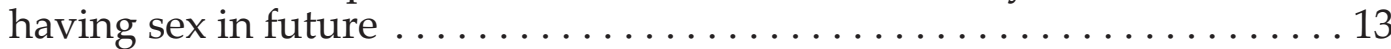

Figure 5: Distribution of respondents by perceived appropriate time for an HIV-positive boy or girl to start having sex . . . . . . . . . . . . 14

Figure 6: Distribution of respondents currently using a condom by the

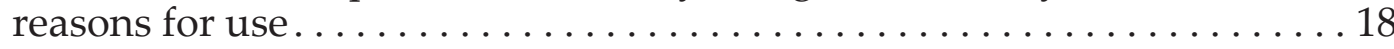

Figure 7: Distribution of respondents who are currently using contraceptives

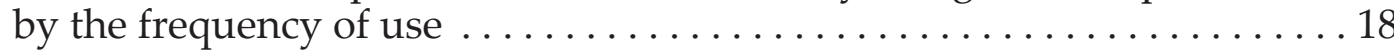

Figure 8: Distribution of pregnancies by outcomes $\ldots \ldots \ldots \ldots \ldots \ldots \ldots \ldots 22$ 


\section{Acronyms}

APHIA

ART

ARV

CCC

$\mathrm{CHW}$

ERC

FGD

FHI

FP

HIV

IRB

IUCD

KNCST

NASCOP

OR

OVC

PDA

PEPFAR

PMTCT

$\mathrm{SRH}$

STI

VCT
AIDS, Population and Health Integrated Assistance

Antiretroviral Treatment

Antiretroviral Drugs

Comprehensive Care Centers

Community Health Worker

Ethics Review Committee

Focus Group Discussion

Family Health International

Family Planning

Human Immunodeficiency Virus

Institutional Review Board

Intra Uterine Contraceptive Device

Kenya National Council of Science and Technology

National AIDS and STI Control Programme

Operations Research

Orphaned and Vulnerable Children

Personal Data Assistant

President's Emergency Plan for AIDS Relief

Prevention of Mother-to-Child Transmission

Sexual and Reproductive Health

Sexually Transmitted Infection

Voluntary Counseling and Testing 


\section{Executive summary}

Evidence from Uganda shows that the surviving population of young people aged 10-19 years who were perinatally and those sexually infected with HIV is rapidly growing due to the increased availability of antiretroviral treatment (ART). These young people are exploring their sexuality-- they are dating (either seeing someone who is HIV-positive as well or are in discordant relationships), some are sexually active, some have experienced a pregnancy, and others strongly desire to have children in future. However, their preventive practices are extremely poor. Whereas the situation is likely to be similar in Kenya, there are no systematic studies in the country to inform sexual and reproductive health (SRH) for adolescents living with HIV.

The objective of this study was to assess the sexual and reproductive health needs of adolescents living with HIV in Kenya with a view to identify and develop interventions that integrate these needs within the existing HIV/AIDS treatment, care and support programs in the country. It was a result of collaboration between Population Council, APHIA II Rift Valley and Coast (Family Health International, FHI), the National AIDS and STI Control Programme (NASCOP), and APHIA II Nairobi and Central (Pathfinder International). It was conducted in Rift Valley and Coast provinces and involved a survey of 455 adolescents aged 15-19 years who are living with HIV, 4 focus group discussions with a subset aged 18-19 years, 12 indepths with adolescent girls who have ever been pregnant, and 10 key informant interviews with service providers/ counselors.

\section{Key findings}

As expected, many of the adolescents living with HIV are vulnerable: Most of them have lost one or both parents while many are out of school largely because of lack of school fees or materials. Most of those who are out of school did not go beyond primary level education which means that they have limited opportunities for advancing in their careers. In terms of schooling, more HIV-positive female than male respondents are disadvantaged. Whereas this also applies to the general population, being HIV-positive compounds further the situation for these female adolescents.

There are programmatic gaps in addressing the sexual and reproductive health needs of HIV-positive adolescents: Key informant interviews with service providers/ counselors show that this is mostly due to service orientation, lack of provider training in SRH counseling for HIV-positive adolescents, inadequate financial and human resources, and the difficulty of dealing with adolescent sexuality in general.

Most HIV-positive adolescents talk to service providers/counselors more than to parents/ guardians about sexual and reproductive health issues: This can largely be attributed to the social and cultural norms that guide discussion of SRH issues between adolescents and adults, especially parents/guardians, in much of subSaharan Africa. In spite of this, one-in-four of the adolescents still found it difficult 
talking to service providers/ counselors about issues that are important to them. This suggests that some of the adolescents might be getting such information from their peers which, as interviews with key informants suggest, might not always be correct, or they could be getting no information at all.

Few of the HIV-positive adolescents belong to any support group: Only about fourin-ten of the HIV-positive adolescents reported belonging to a support group. This suggests that many do not access the kind of support services that the groups offer which include peer support, life skills training, and psychosocial support. It also implies that many might not benefit from critical sexual and reproductive health information for HIV-positive young people which can be channeled through the groups.

Most of the HIV-positive adolescents have ever been in a relationship; many are in or intend to be involved in relationships: Two-in-three of the HIV-positive adolescents have been in a relationship and about four-in-ten of these (i.e. those who have been in a relationship) were still in a relationship by the time of the survey. About eight-in-ten of those who have never been in a relationship intend to be involved in relationships in future while among those who are not married or living with someone, a similar proportion intend to marry in future.

Nearly half of the HIV-positive adolescents desire to have sex; many have had sex or intend to have sex in future: Focus group discussions show that many of them felt this is natural. More than half felt that someone living with HIV should have sex and a similar proportion have had sex. Among those who have had sex, about two-thirds had consensual first sex. Besides, among those who have never had sex, nearly ninein-ten intend to have sex in future with most (three-in-four) of them planning to wait until marriage before having sex.

Although knowledge of contraceptives is high, actual use of the methods is low: Nearly eight-in-ten of the adolescents surveyed know of a contraceptive method and a similar proportion know of a place to get a method. Nonetheless, only about twoin-ten of those who had consensual first sex used a preventive method that first time. In addition, among those who have ever had sex, slightly more than half have ever used a method while less than half reported current use of a method.

\section{There is high rate of unintended pregnancies among HIV-positive adolescent} girls: About two-thirds of sexually active HIV-positive adolescent girls have been pregnant. About one-in-five of these have been pregnant more than once while about seven-in-ten of all the pregnancies are unintended. Respondents' boyfriends were responsible for about six-in-ten of the pregnancies.

Although most of the HIV-positive adolescents intend to have children in future, the majority desire to delay childbearing: Nearly eight-in-ten of the adolescents surveyed intend to have children in future with a significantly higher proportion of male than female respondents expressing such desire. However, nearly nine-in-ten of those who intend to have children in future would like to do so later on in life. 
There is low use of PMTCT compared to antenatal care services among pregnant HIV-positive adolescent girls: Although PMTCT should be part of antenatal care for HIV-positive mothers, the proportion of pregnancies for which mothers received antenatal care is higher than that for which they received PMTCT services. In-depth interviews with a subset of ever pregnant HIV-positive adolescent girls who did not receive PMTCT services suggest that this could be partly because of availability and quality of services offered.

HIV-positive adolescents are mostly worried about infecting others, pregnancy, sero-status disclosure, and sexual violence: More than four-in-five are worried about infecting someone with HIV, two-thirds are worried about pregnancy, while almost a similar proportion are worried about sero-status disclosure and sexual violence. This is further supported by findings from the focus group discussions and key informant interviews with service providers/ counselors.

\section{Programmatic implications}

The need to strengthen the provision of information and services on family planning and HIV prevention: First, most HIV-positive young people engage or desire to engage in sex just like other adolescents. Second, although most of them know of a contraceptive method, actual use is low. It is therefore not surprising that the rate of unintended pregnancies among sexually active HIV-positive adolescent girls is high. Moreover, there is the potential for further spread of HIV, especially if sex occurs with discordant partners. At the same time, most HIV-positive adolescents are worried about infecting others with HIV and pregnancy. All these underscore the need for HIV/AIDS treatment, care and support programs to assess the contraceptive and preventive service needs of adolescents living with HIV, and to strengthen the provision of appropriate information and services to this group of clients.

\section{Programs need to ensure effective provision of PMTCT services for HIV-positive} adolescents during pregnancy: PMTCT services should be an integral component of antenatal care for HIV-positive mothers to reduce the likelihood of vertical transmission of HIV. However, the fact that a substantial proportion of pregnant HIV-positive adolescents received antenatal but not PMTCT services implies that there are still gaps in the provision of these services. HIV/AIDS programs therefore need to identify HIV-positive adolescent girls who are pregnant, provide support including information on and referral for the full range of antenatal care and PMTCT services, and put in place follow-up mechanisms to ensure that they receive the services.

There is need to update the existing counseling and support packages to include sexual and reproductive health information and services: This will equip service providers/ counselors with a tool that they can use: 1) as a checklist to determine the relevant SRH items to discuss with HIV-positive adolescents during counseling sessions; and 2) to systematically assess the SRH information and service needs of HIV-positive adolescents with a view to addressing such needs in a timely manner or making appropriate referral. 
Updating the counseling and support packages need to be accompanied with training/ re-orienting service providers/ counselors: This will enhance provider capacity to handle the additional tasks and thus enable them to carry out their work effectively. Programs will also need to ensure that the updated package is part of the curriculum for pre-service training of providers/ counselors.

There is need to put in place mechanisms for involving parents/guardians in discussion of sexual and reproductive health issues with HIV-positive adolescents: Although the discussion of SRH issues between parents/ guardians and adolescents faces socio-cultural challenges, HIV/AIDS programs need to establish mechanisms for involving parents/guardians in discussing these issues with the adolescents. This should involve equipping parents/ guardians with skills for handling adolescent SRH issues. There is also need to encourage HIV-positive young people to freely discuss the SRH issues not only with parents/ guardians but also with service providers/ counselors during counseling sessions given that some still find it difficult to talk to providers about these issues.

Programs need to strengthen support groups for HIV-positive adolescents and encourage them to join the groups: Support groups for people living with HIV are a source of peer and psychosocial support as well as life skills training. They are also potential avenues for channeling appropriate SRH information for the adolescents. However, the fact that many HIV-positive adolescents do not belong to the groups underscores the need for programs to strengthen these groups, especially for young people, and to encourage HIV-positive adolescent clients to join the groups.

Programs also need to strengthen life skills training for HIV-positive adolescents: Many of the HIV-positive adolescents are vulnerable on account of the fact that they are young, they are living with a chronic illness, many have lost one or both parents, and the majority are out of school. In addition, most of those who are out of school did not go beyond primary education, which implies that prospects for career advancement are limited for many of them. HIV/AIDS programs therefore need to strengthen life skills training to enable them make informed choices, balance responsibility with sexual and reproductive desires, and to realize their potential in life. 


\section{Background}

Population Council's work in Uganda shows that the surviving population of young people aged 10-19 years who were perinatally infected with HIV is rapidly growing due to the increased availability of antiretroviral treatment (ART). These young people are beginning to explore their sexuality-- they are dating (either seeing someone who is HIV-positive as well or are in discordant relationships), some are sexually active, some have experienced a pregnancy, and others strongly desire to have children in future. There are reasons to believe that a similar situation applies to Kenya. To begin with, Kenya-- like Uganda-- has been characterized by high HIV prevalence with adult prevalence peaking at around 10\% in the late 1990s (NASCOP 2005). Second, the shift in the global discourse from the cost-effectiveness arguments that drove the prevention programs to human rights and equity considerations that emphasize prevention and care has led to rapid roll-out of ART in sub-Saharan Africa, Uganda and Kenya included (Hardon 2005). Despite the growing number of young people living with HIV as a result of the roll-out of ART, there are no systematic studies in Kenya to inform sexual and reproductive health (SRH) for them.

The Uganda experience shows that the majority of these young people are very worried about becoming pregnant or impregnating someone, disclosing their HIV status, infecting others and re-infecting themselves; yet their preventive practices are extremely poor (Bakeera-Kitaka et al. 2008; Birungi et al. 2008; 2009a; 2009b). Counseling services for these young people have not provided pragmatic solutions for those sexually active beyond sexual self-restraint. In most centers, young people living with HIV are still treated under pediatric care with little preparation for adult life. With no targeted services for this population, many opt out when they experience a pregnancy. This emerging evidence underscores the need to recognize this group of young people in Kenya as well, learn more about their lives, identify their preventive information needs and service priorities, and design appropriate programs for their special needs. This study therefore sought to answer the following question: What are the preventive services needs of adolescents living with HIV and how best can these needs be met?

Identifying appropriate preventive information and service priorities for young people living with HIV now maturing into adolescence and adulthood is an anticipated need and challenge to NASCOP and to APHIA II partners. This study was expected to generate evidence to be utilized in designing effective comprehensive preventive services for adolescents living with HIV. The study reinforced and cut across three areas emphasized by the US President's Emergency Plan for AIDS Relief (PEPFAR): prevention, treatment and care. Effective positive preventive services, especially around abstinence, family planning, partner notification and prevention of mother-to-child transmission (PMTCT) are particularly crucial in stemming HIV transmission from this population. HIV/AIDS programs need to provide these young people with information, life skills and 
practical support to be able to make informed decisions, act responsibly, negotiate vital aspects of their lives, and avoid undesired consequences like unwanted pregnancies, infection of others and self re-infection. There is also need to develop and test integrated counseling strategies that emphasize dual protection and family planning.

\section{Study objectives}

- To assess the sexual and reproductive health needs of young people aged 1519 years who are living with HIV in Kenya; and

- To identify and develop interventions that integrate these needs into the existing HIV/AIDS treatment, care and support programs in the country.

\section{Methodology}

The study was a collaboration between NASCOP, Population Council (APHIA II Operations Research), Family Health International (APHIA II Rift Valley and Coast), and Pathfinder International (APHIA II Nairobi and Central). It was conducted in Rift Valley and Coast Provinces of Kenya between November and December 2009. It involved both quantitative survey and qualitative interviews with adolescents aged 15-19 years who are living with HIV, were aware of their HIV sero-status, and were willing and able to talk about their inner lives. The participants were identified and recruited through the existing orphaned and vulnerable children (OVC) programs, comprehensive care centers (CCCs), youth counseling centers, and voluntary counseling and testing (VCT) centers that are supported by APHIA II partners in the two provinces. Service providers/ counselors, community healthcare workers, and social workers assisted with the identification and mobilization of the respondents.

The research team first obtained permission from the management of the centers/ facilities working with adolescents living with HIV. The team then held meetings with service providers/ counselors, CHWs, and social workers (identified by APHIA II partners) who also work with the adolescents. The purpose of these meetings was to: 1) introduce the study and its procedures to the providers; and 2) to request them to identify, mobilize, and link willing participants and their respective parents/ guardians with the research team after explaining to them the purpose of the study. The research team then obtained written consent from willing participants before conducting interviews. For adolescents aged 15-17 years, written consent was first obtained from the parent/ guardian, before obtaining assent from the adolescents themselves. For those aged 18-19 years and emancipated minors (those aged 15-17 years and living alone, married, or taking care of siblings), only individual written consent was obtained.

The quantitative survey involved structured interviews using hand-held Personal Data Assistants (PDAs). The interviews were conducted by trained young research assistants who received training on the study procedures, data collection, ethics, and the use of PDAs over a one-week period. The survey tool was adapted and modified 
from the one used for a similar study in Uganda (Birungi et al. 2008). It was then translated into Kiswahili, the national language, before being programmed in PDAs. Information was collected on respondents' background characteristics, access to information and support services, relationships and dating, sexual behavior and desires, knowledge and use of preventive/ contraceptive methods, pregnancy and childbearing experiences and intentions, pregnancy outcomes and use of maternal health services, experiences with physical and sexual violence, and issues of selfesteem. The interview setting was agreed upon between the research assistant and the respondents. A total of 455 female and male adolescents were identified for individual interviews; 2 of these did not complete the interviews because of emotional breakdown.

Besides the quantitative survey, 4 focus group discussions (FGDs) were held with a subset of the survey participants aged 18-19 years. This age group was chosen for the FGDs because they could provide individual written consent given that there was limited time to allow for obtaining parental/ guardian consent for those aged 15-17 years. One FGD was held with female and another with male adolescents in each site (Rift Valley and Coast). The purpose of the FGDs was to determine group opinions, perceptions, attitudes around their sexuality as well as their SRH information and service needs. Two research assistants conducted the FGDs: one facilitator and one note taker. Each FGD had, on average, 5 participants.

In addition, a total of 12 in-depth interviews (6 in each site) were conducted with HIV-positive adolescent girls who have ever been pregnant. The purpose was to gain a more in-depth understanding of their experiences with maternal and child health services including PMTCT, assistance during delivery, post-natal care, and child health services. Unstructured interviews were also conducted with 6 service providers/ counselors in Coast province, and $10 \mathrm{CHWs}$ and social workers in Rift Valley province, to understand the issues around SRH counseling for HIVpositive adolescents from the providers' point of view. The service providers were purposively selected by APHIA II partners based on how frequently they interacted with HIV-positive adolescents.

The quantitative data was analyzed using STATA. The results are presented in the form of frequencies and percentages by sex of the respondents. The data from the focus group discussions and in-depth interviews were tape-recorded with the permission of the study participants, transcribed, typed in Word, and analyzed for content.

The research team obtained ethical clearance for the study from the Institutional Review Board (IRB) of the Population Council and the Ethics Review Committee of the Kenya Medical Research Institute (KEMRI). The Kenya National Council of Science and Technology (KNCST) provided the research clearance while NASCOP granted the research team the permission to access the CCCs within the Ministry of Health facilities. 


\section{Characteristics of adolescents living with HIV}

Female respondents comprised about two-thirds (63\%) of the sample, which could be a reflection of the fact that in Kenya, as elsewhere in sub-Saharan Africa, women are disproportionately affected by and infected with HIV compared to men. Although estimates from the 2007 Kenya AIDS Indicator Survey show that the two provinces have almost similar HIV prevalences $(8 \%$ and $7 \%$ in Coast and Rift Valley provinces respectively; NASCOP 2008), three-in-five (60\%) of the respondents were from Coast province (Table 1). The difference in the number of respondents could largely be due to the sparseness of Rift Valley compared to Coast province, which has implications for the distribution of HIV-positive respondents who could be reached. With respect to age, the distribution shows a U-shaped pattern with more than half (59\%) of the respondents being found at the two extreme ages, that is, 15 or 19 years ( $61 \%$ of female and $56 \%$ of male respondents; $\mathrm{p}=0.30)$. The average age of the respondents was 17 years with no significant difference between female and male participants (Table 1).

Table 1: Distribution of survey participants by background characteristics

\begin{tabular}{|c|c|c|c|}
\hline Characteristics & $\begin{array}{r}\text { Female } \\
(\mathrm{N}=\mathbf{2 8 8})\end{array}$ & $\begin{array}{r}\text { Male } \\
(\mathrm{N}=167)\end{array}$ & $\begin{array}{r}\text { Both sexes } \\
(\mathrm{N}=455)\end{array}$ \\
\hline Mean age (years) & 17 & 17 & 17 \\
\hline \multicolumn{4}{|l|}{ Age distribution (\%) } \\
\hline $\begin{array}{l}15 \\
16\end{array}$ & $\begin{array}{r}24 \\
9\end{array}$ & $\begin{array}{r}30 \\
16^{*}\end{array}$ & $\begin{array}{l}26 \\
12\end{array}$ \\
\hline 17 & 12 & 12 & 12 \\
\hline 18 & 18 & 16 & 17 \\
\hline $\begin{array}{l}19 \\
\text { Missing }\end{array}$ & $\begin{array}{r}37 \\
0\end{array}$ & $\begin{array}{r}26^{*} \\
1\end{array}$ & $\begin{array}{r}33 \\
0\end{array}$ \\
\hline \multicolumn{4}{|l|}{ Study site (\%) } \\
\hline Rift Valley & 44 & $34^{*}$ & 40 \\
\hline Coast & 56 & $67^{*}$ & 60 \\
\hline \multicolumn{4}{|l|}{ Parents' living arrangements (\%) } \\
\hline Living together & 23 & 24 & 23 \\
\hline $\begin{array}{l}\text { Divorced/ separated } \\
\text { Both parents dead }\end{array}$ & 8 & 10 & 99 \\
\hline $\begin{array}{l}\text { Both parents dead } \\
\text { Mother dead }\end{array}$ & $\begin{array}{l}35 \\
13\end{array}$ & $\begin{array}{l}36 \\
14\end{array}$ & $\begin{array}{l}35 \\
14\end{array}$ \\
\hline Father dead & 21 & 15 & 19 \\
\hline Don't know & 0 & 1 & 0 \\
\hline \multicolumn{4}{|l|}{ Lives with at least one biological parent (\%) } \\
\hline Yes & 37 & 40 & 38 \\
\hline No & 58 & 55 & 57 \\
\hline Missing & 5 & 6 & 6 \\
\hline \multicolumn{4}{|l|}{ Has at least one surviving sibling (\%) } \\
\hline $\begin{array}{l}\text { Yes } \\
\text { No }\end{array}$ & 91 & 89 & $\begin{array}{l}90 \\
10\end{array}$ \\
\hline \multicolumn{4}{|l|}{ Lives with at least one sibling in household (\%) } \\
\hline Yes & 62 & 71 & 65 \\
\hline No & 38 & 30 & 35 \\
\hline \multicolumn{4}{|l|}{ Currently attending school (\%) } \\
\hline Yes & 36 & $52^{* *}$ & 42 \\
\hline No & 64 & $48^{*}$ & 58 \\
\hline
\end{tabular}


More than half (57\%) of the respondents were not living with any biological parents ( $58 \%$ of female and $55 \%$ of male respondents; $\mathrm{p}=0.53$ ). This was mainly because more than two-thirds (68\%) had lost one or both parents with no significant difference between female and male respondents ( $69 \%$ versus $65 \%$; $\mathrm{p}=0.38$ ). In addition, whereas nine-in-ten $(90 \%)$ of the respondents had at least one surviving sibling, only about two-in-three $(65 \%)$ lived with a sibling in the same household $(62 \%$ of the female and $71 \%$ of the male respondents; $\mathrm{p}=0.051$ ). These are indications that most of the young people living with HIV are vulnerable.

The large number of respondents (58\%) who were out of school is a further indication of the vulnerability of HIV-positive young people (Table 1). A significantly higher proportion of HIV-positive adolescent girls than boys were out of school ( $64 \%$ versus $48 \%$; $\mathrm{p}<0.05$ ), suggesting that HIV-positive adolescent girls face greater vulnerability compared to boys. Respondents who were not attending school were asked the major reason for non-attendance. About two-in-five (42\%) mentioned lack of school fees and materials with no significant difference between female and male respondents ( $\mathrm{p}=0.54$; Figure 1$)$. Whereas nearly one-in-four $(24 \%)$ reported completing the given level, a significantly higher proportion of male than female respondents reported having completed $(\mathrm{p}<0.01)$. In contrast, a significantly higher proportion of female than male respondents reported never attending school $(p<0.05)$ or having dropped out because of pregnancy/ having a child ( $<0.01$; Figure 1).

Figure 1: Distribution of respondents not currently attending school by the major reason for non-attendance

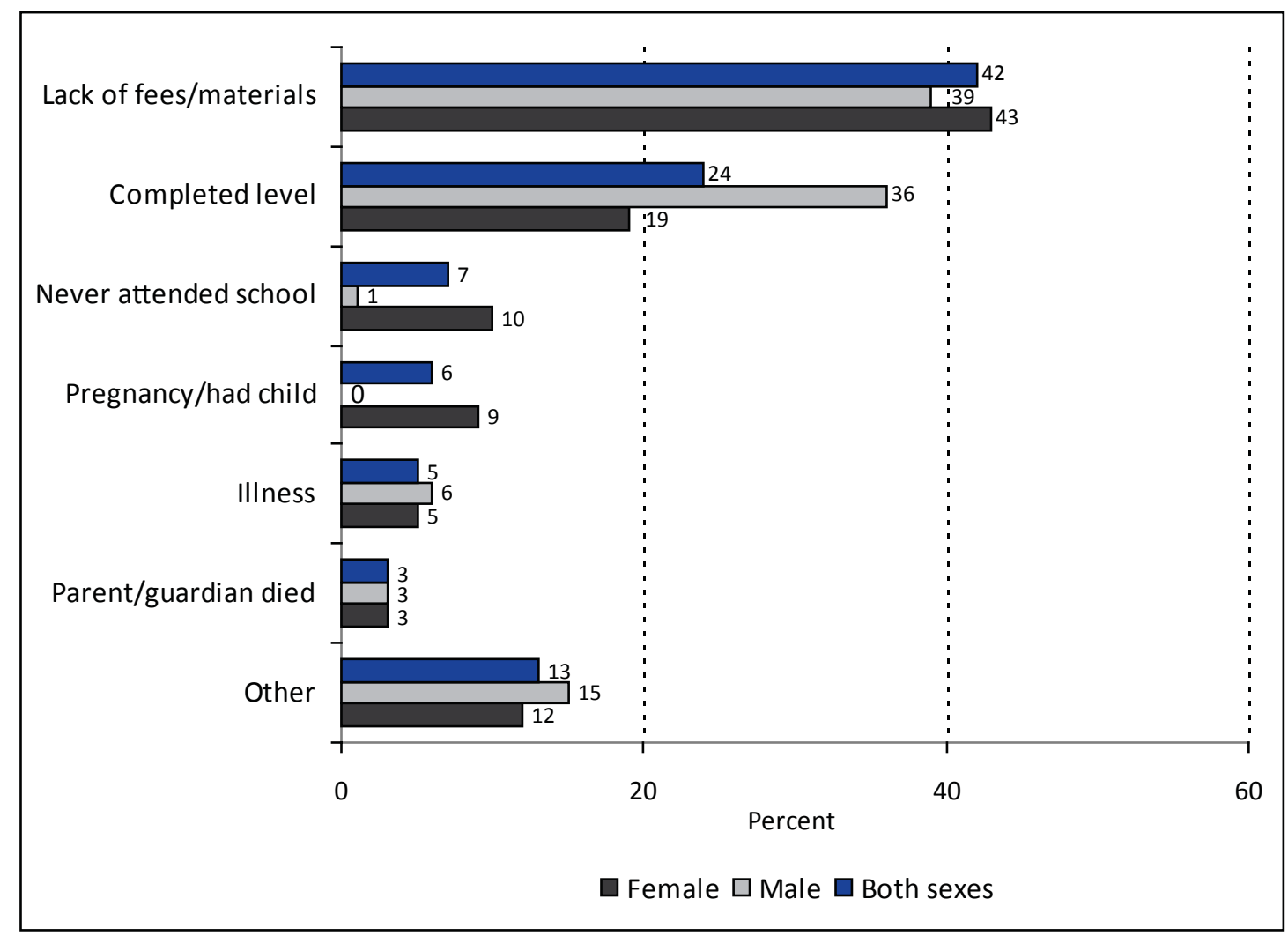


Among respondents who had ever attended school but were out of school at the time of the survey, the majority (71\%) reached primary level (Figure 2), which suggests that opportunities for career advancement are limited for many of them. A slightly higher proportion of female than male respondents reached primary level (72\% versus $67 \%$; $\mathrm{p}=0.42$ ) while a slightly higher proportion of male than female respondents reached secondary level and above (33\% versus $27 \%$; $=0.33$ ). Although almost a similar proportion (76\%) of those attending school were in primary, it is not certain how many may proceed to higher levels.

Figure 2: Distribution of respondents by the level of education and by whether they are in or out of school

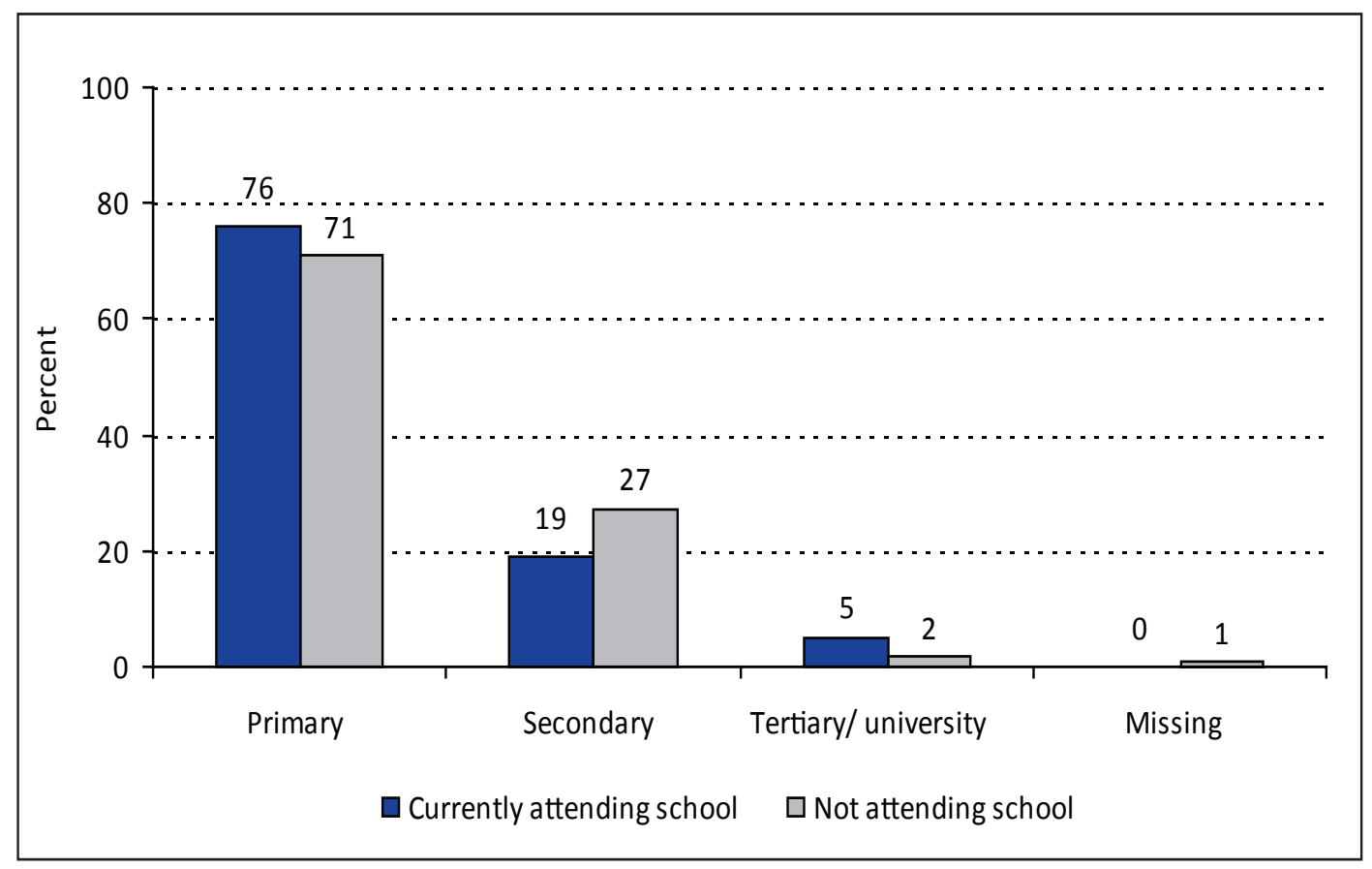

\section{Service provision, information and support}

Population Council's work in Uganda showed that the available counseling services are not responsive to the needs of HIV-positive adolescents as the service providers/ counselors mostly focus on their responsibilities and not their needs and rights (Birungi et al. 2008). Other challenges have to do with service orientation (pediatric or adult care), lack of provider training to handle the SRH needs of HIVpositive adolescents, and financial and human resource constraints. Key informant interviews with service providers/ counselors in Kenya revealed similar challenges as the following excerpts show:

Yeah, because from [age] 13 we consider them now to be attending the adult CCC. But normally you find that weaning them off from the pediatric CCC is somehow a problem. They feel they do not cope here. They normally tend to take some time in transferring them, because they have to counsel them to make them understand that now they have to be attended at the adult CCC (Key informant interview No. 2, Coast). 
One, we need support in terms of manpower [to be able to give a comprehensive package of SRH counseling and services to HIV-positive adolescents]. I am talking of putting someone in a strategic point and saying this is what he will be doing. When we talk of defaulter tracing, someone is put in charge to trace these defaulters. We talk of adherence, someone is put in charge. If it is VCT, someone has to be put there to oversee and should be paid for. Not that he is volunteering. You know volunteering you come at your will (Key informant interview No. 6, Coast).

Participants in the survey were also asked whether they found it easy or difficult to talk to a service provider or counselor about things that are important to them. Slightly more than one-in-four (26\%) reported finding it difficult to talk to a service provider/ counselor with no significant difference between female and male respondents ( $25 \%$ versus $27 \%$; $=0.64$ ). They were also asked whether they have ever talked to a service provider or counselor and parent or guardian about sexual and reproductive health issues such as dating and relationships, sex, contraceptives, pregnancy, and living with HIV. Respondents reported having talked to service providers/ counselors most about living life as a young person with HIV (76\%), hopes about self $(60 \%)$, sex (56\%), fears in life (53\%), and how pregnancy occurs $(50 \%)$. In all cases, there is no significant difference in the proportions of female and male respondents reporting having talked to service providers/ counselors about these aspects.

Table 2: Percentage of respondents who ever talked with service providers and parents/ guardians about sexual and reproductive health issues

\begin{tabular}{|c|c|c|c|c|c|c|}
\hline \multirow{2}{*}{ Issue talked about } & \multicolumn{3}{|c|}{$\begin{array}{c}\text { Service provider/ counselor } \\
(\%)\end{array}$} & \multicolumn{3}{|c|}{$\begin{array}{l}\text { Parent/ guardian } \\
\text { (\%) }\end{array}$} \\
\hline & $\begin{array}{r}\text { Female } \\
(\mathrm{N}=288)\end{array}$ & $\begin{array}{r}\text { Male } \\
(\mathrm{N}=167)\end{array}$ & $\begin{array}{r}\text { Both } \\
(\mathrm{N}=455)\end{array}$ & $\begin{array}{r}\text { Female } \\
(\mathrm{N}=\mathbf{2 8 8})\end{array}$ & $\begin{array}{r}\text { Male } \\
(\mathrm{N}=167)\end{array}$ & $\begin{array}{r}\text { Both } \\
(\mathrm{N}=455)\end{array}$ \\
\hline Menstruation & 49 & $\mathrm{~N} / \mathrm{A}$ & $\mathrm{N} / \mathrm{A}$ & 57 & $\mathrm{~N} / \mathrm{A}$ & $\mathrm{N} / \mathrm{A}$ \\
\hline Dating and relationships & 43 & 45 & 44 & 38 & 34 & 37 \\
\hline How pregnancy occurs & 53 & 44 & 50 & 49 & $28^{* *}$ & 41 \\
\hline Method of birth control & 46 & 41 & 44 & 41 & $27^{* *}$ & 36 \\
\hline Having/ not having children & 39 & 43 & 40 & 36 & 34 & 35 \\
\hline Sex & 56 & 57 & 56 & 38 & 35 & 37 \\
\hline Hopes about self & 59 & 63 & 60 & 63 & 67 & 64 \\
\hline Fears in life & 51 & 55 & 53 & 51 & 50 & 51 \\
\hline $\begin{array}{l}\text { Living life as a young person } \\
\text { with HIV }\end{array}$ & 76 & 76 & 76 & 62 & 70 & 64 \\
\hline Wet dreams & $\mathrm{N} / \mathrm{A}$ & 32 & $\mathrm{~N} / \mathrm{A}$ & $\mathrm{N} / \mathrm{A}$ & 19 & $\mathrm{~N} / \mathrm{A}$ \\
\hline Body size & 32 & 35 & 33 & 37 & $26^{*}$ & 33 \\
\hline Masturbation & 14 & $23^{*}$ & 17 & 11 & 15 & 12 \\
\hline
\end{tabular}

With respect to talking to parents/ guardians, respondents reported that they talked to them most about living life as a young person with HIV (64\%), hopes about self $(64 \%)$, and fears in life (51\%) with no significant difference between female and male respondents (Table 2). However, a significantly higher proportion of female 
than male respondents reported talking to parents/ guardians about how pregnancy occurs $(p<0.01)$, methods of birth control $(p<0.01)$, and body size $(p<0.05)$. It is worth noting, however, that in most cases, the proportion of respondents reporting talking to parents/guardians about these issues is lower than that reporting talking to service providers/ counselors (Table 2).

Having friends that they can talk to and belonging to support groups for HIVpositive young people where they can meet and share experiences are ways of ensuring psychosocial support for adolescents living with HIV. However, nearly one-in-three $(32 \%)$ of the respondents reported that they did not have any friends they could easily talk to about their lives $37 \%$ of the female and $25 \%$ of the male respondents; $\mathrm{p}<0.01$ ). In addition, only $39 \%$ reported belonging to support groups for HIV-positive young people with no significant difference between female and male respondents ( $40 \%$ versus 37\%; $\mathrm{p}=0.53$ ). Among those who belonged to such groups, slightly more than four-in-five (81\%) never felt being discriminated against because of their membership to the groups, perhaps reflecting the fact that the groups mostly comprise of those who have accepted their HIV sero-status (Table 3). A similar proportion never felt being discriminated against as a result of receiving services from the HIV/AIDS treatment, care or support center. Nonetheless, onein-four $(25 \%)$ of the respondents felt some form of discrimination because of their HIV status. In all cases, there is no significant difference between female and male respondents who felt that way.

Table 3: Distribution of respondents by frequency of feelings of discrimination

\begin{tabular}{|c|c|c|c|}
\hline Reason and frequency of feelings & $\begin{array}{r}\text { Female } \\
(\%)\end{array}$ & $\begin{array}{r}\text { Male } \\
(\%) \\
\end{array}$ & $\begin{array}{r}\text { Both sexes } \\
(\%)\end{array}$ \\
\hline Belonging to a support group for HIV-positive ${ }^{a}$ & $(\mathrm{~N}=114)$ & $(\mathrm{N}=62)$ & $(\mathrm{N}=176)$ \\
\hline Often & 6 & 2 & 5 \\
\hline Sometimes & 8 & 11 & 9 \\
\hline Rarely & 5 & 3 & 5 \\
\hline Never & 80 & 84 & 81 \\
\hline Missing & 2 & 0 & 1 \\
\hline Receiving services at HIV/AIDS centre & $(N=288)$ & $(N=167)$ & $(N=455)$ \\
\hline Often & 6 & 4 & 5 \\
\hline Sometimes & 7 & 8 & 7 \\
\hline Rarely & 3 & 5 & 4 \\
\hline Never & 82 & 80 & 81 \\
\hline Missing & 2 & 3 & 2 \\
\hline Being HIV-positive & $(\mathrm{N}=288)$ & $(\mathrm{N}=167)$ & $(\mathrm{N}=455)$ \\
\hline Often & 10 & $5^{*}$ & 8 \\
\hline Sometimes & 12 & 10 & 11 \\
\hline Rarely & 5 & 7 & 6 \\
\hline Never & 72 & 75 & 73 \\
\hline Missing & 2 & 3 & 2 \\
\hline
\end{tabular}




\section{Dating and relationships}

Young people living with HIV do not primarily construct their lives around their illness; instead, they aspire to lead normal lives just like other adolescents, including engaging in dating and relationships (Birungi et al. 2007). This is supported by the fact that about two-in-three (66\%) of the respondents reported ever having had a boyfriend or girlfriend (Table 4). Although not statistically significant, a higher proportion of female than male respondents reported ever being in a relationship (68\% versus $61 \% ; p=0.13)$.

Table 4: Distribution of respondents by experiences with relationships and dating

\begin{tabular}{|c|c|c|c|}
\hline Relationships and dating indicators & $\begin{array}{r}\begin{array}{r}\text { Female } \\
(\%)\end{array} \\
\end{array}$ & $\begin{array}{r}\text { Male } \\
(\%) \\
\end{array}$ & $\begin{array}{r}\text { Both sexes } \\
(\%)\end{array}$ \\
\hline Ever had a boyfriend/ girlfriend ${ }^{a}$ & 68 & 61 & 66 \\
\hline Currently in a relationship ${ }^{b}$ & 45 & 42 & 44 \\
\hline Relative age of current partner & $(\mathrm{N}=89)$ & $(\mathrm{N}=43)$ & $(N=132)$ \\
\hline Younger & 1 & $47^{* *}$ & 16 \\
\hline Same age & 7 & $30^{* *}$ & 14 \\
\hline Older & 83 & $21^{* *}$ & 63 \\
\hline Much older & 8 & 2 & 6 \\
\hline Missing & 1 & 0 & 1 \\
\hline Seriousness of relationship & $(\mathrm{N}=89)$ & $(\mathrm{N}=43)$ & $(\mathrm{N}=132)$ \\
\hline Not serious & 19 & 19 & 19 \\
\hline Serious but no intention to marry & 21 & 19 & 21 \\
\hline Serious/ might lead to marriage/ married & 51 & 63 & 55 \\
\hline Missing & 9 & $0^{*}$ & 6 \\
\hline Ever engaged in ${ }^{c}$ & $(\mathrm{~N}=288)$ & $(\mathrm{N}=167)$ & $(\mathrm{N}=455)$ \\
\hline Kissing & 53 & 49 & 52 \\
\hline Touching & 57 & 53 & 55 \\
\hline Fondling & 57 & 52 & 55 \\
\hline Masturbation & 16 & 19 & 17 \\
\hline Hugging & 56 & 54 & 55 \\
\hline Fantasizing about sex & 44 & $56^{*}$ & 49 \\
\hline With current partner ${ }^{c}$ & $(\mathrm{~N}=89)$ & $(N=43)$ & $(\mathrm{N}=132)$ \\
\hline Kiss on lips & 69 & 67 & 68 \\
\hline Hold hands & 98 & 91 & 96 \\
\hline Hug & 90 & 88 & 89 \\
\hline Touch private parts & 56 & 63 & 58 \\
\hline \multicolumn{4}{|c|}{$\begin{array}{l}{ }^{a} \text { Among all respondents ( } 288 \text { female and } 167 \text { male respondents); }{ }^{b} \text { Among those who have ever } \\
\text { had boyfriends / girlfriends ( } 196 \text { female and } 102 \text { male respondents); }{ }^{\circ} \text { Questions allowed for } \\
\text { multiple responses, percentages do not therefore sum to } 100 \text {; Differences between male and } \\
\text { female respondents are significant at: }{ }^{*} \mathrm{p}<0.05 ;{ }^{* *} \mathrm{p}<0.01 \text {. }\end{array}$} \\
\hline
\end{tabular}

Among those who have ever been in a relationship, 44\% were in a relationship at the time of the survey with no significant difference between female and male respondents $(\mathrm{p}=0.62)$. More than half $(55 \%)$ of those with boyfriends/ girlfriends regarded the relationships serious enough to lead to marriage or were already married. In addition, a significantly higher proportion of male than female respondents reported that their current partners were younger than or of the same age as them. In contrast, a significantly higher proportion of female than male respondents reported that their current partners were generally older than them 
(Table 4).

More than half of those who have been in relationships reported having ever engaged in kissing (52\%), touching (55\%), fondling (55\%), and hugging (55\%). About half (49\%) also reported having ever fantasized about sex (Table 4). Except for fantasizing about sex, there is no significant difference in the proportions of female and male respondents that have ever engaged in the other expressions of sexuality. Moreover, most of those who were in relationships at the time of the survey reported engaging in kissing on the lips (68\%), holding hands (96\%), hugging $(89 \%)$, and touching private parts $(58 \%)$ with their partners, again with no significant difference between female and male respondents.

Respondents who have never been in a relationship were asked whether they intend to have boyfriends/ girlfriends in future. Nearly four-in-five $(79 \%)$ reported that they would want to be in such relationships in future (80\% of the female versus $77 \%$ of the male respondents; $\mathrm{p}=0.65)$. Similarly, among those who were not married or living with anyone, almost a similar proportion (82\%) indicated that they intend to marry in future. A significantly higher proportion of male than female respondents who were not married or living with anyone reported intending to marry in future $(88 \%$ versus $78 \%$; $<<0.01)$. The desire to have sex, marry and have children among HIV-positive adolescents was also evident from the key informant interviews with providers:

Some of them even ask you they want to marry. When they come they are open they ask you they want to marry. At times you even decide for them, "Don't go with somebody whom you do not know his or her status." If you want to go on you have to know the status. Then if she or he is also positive then you can go ahead and marry (Key informant interview No. 2, Coast).

There are some who can come to you or to me and say, "Daktari [Doctor], what I feel is that I want to have sex..." (Key informant interview No. 1, Coast).

All respondents were further asked what their choice of partner would be if they are to be involved in relationships. Slightly more than one-in three (34\%) preferred an HIV-positive partner (Figure 3). Three-in-ten (30\%) preferred an HIV-negative partner while a similar proportion preferred anybody. In all cases, there is no significant difference between female and male respondents although a slightly higher proportion of female than male respondents reported preference for an HIVpositive partner while a slightly higher proportion of male than female respondents preferred an HIV-negative partner (Figure 3). 
Figure 3: Distribution of respondents by preferred choice of boyfriend/ girlfriend/ partner

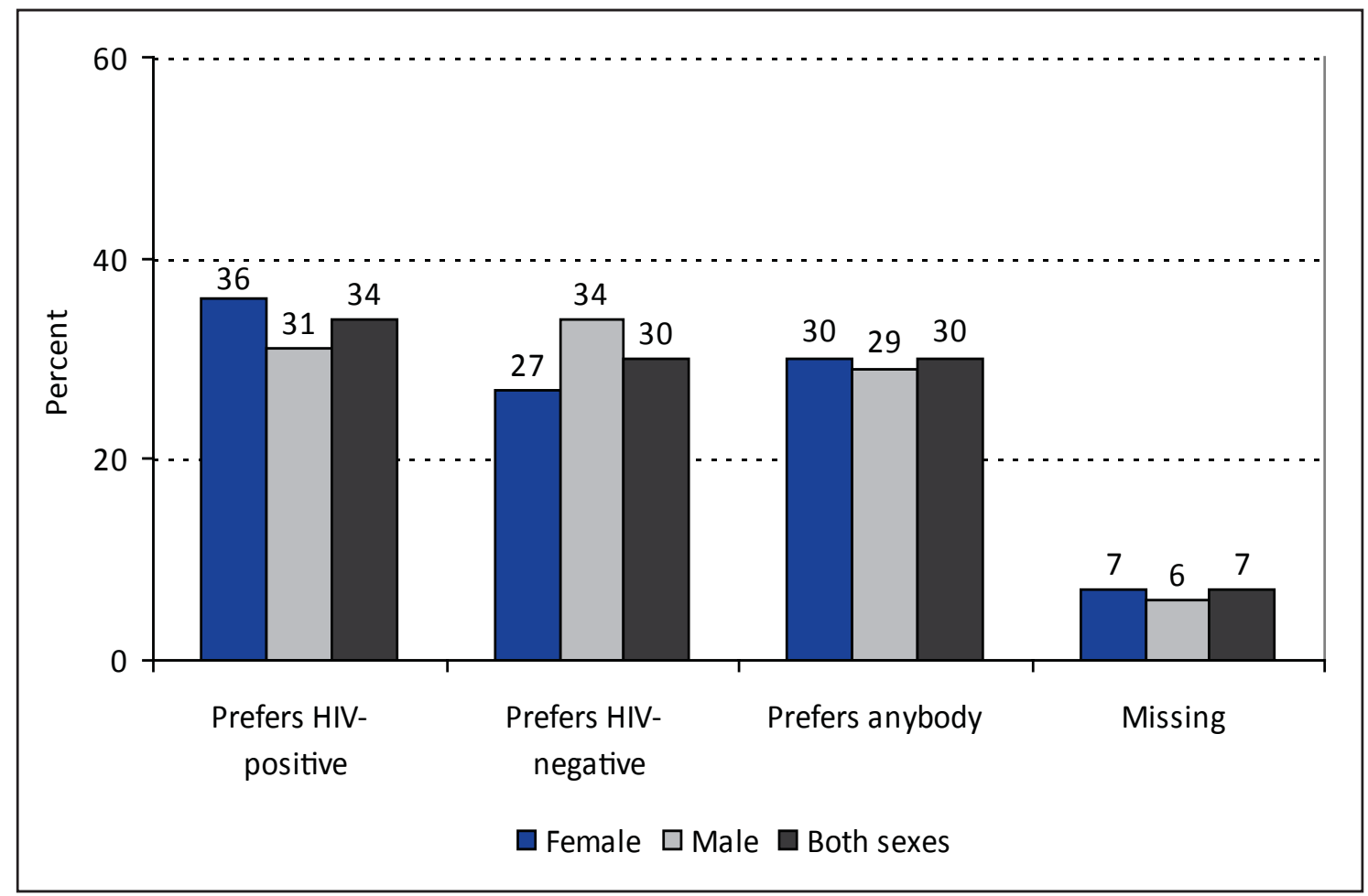

\section{Sexual desires and behavior}

Adolescence is a period when most young people become conscious about and explore their sexuality and many participants in the focus group discussions expressed the general feeling that this is natural:

According to me any youth who is perfectly normal has to think about sex (19year old female participant, No. 4, Coast FGD).

He [hypothetical HIV-positive boy on ART] might be thinking about love... The way in which they can love each other... He is a boy, so he thinks about how he can get a wife (19-year old male participant, No. 2, Rift Valley FGD).

If your mind tells you it wants, it takes you... The mind gives you pressure to go and approach the girl (19-year old male participant, No. 2, Coast FGD).

When you start thinking about your boyfriend, you start feeling the "steam" rising (18-year old female participant, No. 1, Rift Valley FGD).

In addition, $44 \%$ of all survey participants reported that they desire to have sex ( $43 \%$ of the female and $46 \%$ of the male respondents; $p=0.53$ ). A significantly higher proportion of male than female respondents who reported desiring to have sex 
thought about it most of the time (Table 5). Slightly more than half (54\%) had ever had sexual intercourse. It is also worth noting that contrary to sexual behavior literature where more boys/ men than girls/ women report sexual encounters, a significantly higher proportion of female than male respondents reported having had sex. However, there is no significant difference in the mean age at first sex between female and male respondents.

Table 5: Distribution of respondents by sexual desires and behavior

\begin{tabular}{|c|c|c|c|}
\hline Sexual desires and behavior indicators & Female & Male & Both sexes \\
\hline Ever desires to have sex $(\%)^{a}$ & 43 & 46 & 44 \\
\hline Frequency of thinking about sex (\%) & $(N=124)$ & $(\mathrm{N}=75)$ & $(\mathrm{N}=199)$ \\
\hline Most of the time & 5 & $13^{*}$ & 8 \\
\hline Sometimes & 52 & 57 & 54 \\
\hline Rarely & 27 & 23 & 26 \\
\hline Never & 15 & $7^{*}$ & 12 \\
\hline Missing & 1 & $0^{*}$ & 1 \\
\hline Ever had sex $(\%)^{a}$ & 60 & $44^{* *}$ & 54 \\
\hline Mean and median age at first sex & $(N=173)$ & $(\mathrm{N}=74)$ & $(\mathrm{N}=247)$ \\
\hline Mean & 15 & 15 & 15 \\
\hline Median & 15 & 15 & 15 \\
\hline Circumstances of first sex (\%) & $(N=173)$ & $(\mathrm{N}=74)$ & $(\mathrm{N}=247)$ \\
\hline Forced/ raped & 14 & 8 & 12 \\
\hline Tricked & 20 & $7^{* *}$ & 16 \\
\hline Persuaded with money & 5 & 5 & 5 \\
\hline Both willing/ wanted to have sex & 59 & $78^{* *}$ & 65 \\
\hline Missing & 2 & 1 & 2 \\
\hline Relationship to first sexual partner (\%) & $(\mathrm{N}=173)$ & $(\mathrm{N}=74)$ & $(\mathrm{N}=247)$ \\
\hline Husband/ wife & 9 & $1^{*}$ & 7 \\
\hline Steady boyfriend/ girlfriend & 61 & $45^{*}$ & 56 \\
\hline Friend/ acquaintance & 21 & $49^{* *}$ & 30 \\
\hline Stranger & 4 & 1 & 3 \\
\hline Relative & 1 & 1 & 1 \\
\hline Other & 4 & 3 & 3 \\
\hline Missing & 1 & 0 & 1 \\
\hline Relative age of first sexual partner (\%) & $(\mathrm{N}=149)$ & $(N=68)$ & $(\mathrm{N}=217)$ \\
\hline Younger & 3 & $25^{* *}$ & 10 \\
\hline Same age & 18 & $32^{*}$ & 22 \\
\hline Older & 67 & $34^{* *}$ & 57 \\
\hline Much older & 12 & 9 & 11 \\
\hline
\end{tabular}

About two-in-three (65\%) of those who had ever had sex reported consensual first sex, that is, both were willing or wanted to have sex. A significantly higher proportion of male than female respondents reported consensual first sex while a significantly higher proportion of female than male respondents reported that they were tricked into having first sex (Table 5). In more than half (56\%) the cases, the first 
sexual encounter was with a steady boyfriend or girlfriend. A significantly higher proportion of female than male respondents reported that the first sexual partner was a steady boyfriend/ girlfriend while a significantly higher proportion of male than female respondents reported that their first sexual partner was just a friend or an acquaintance. Moreover, consistent with adolescent sexual behavior literature, almost twice as many female as male respondents reported that the first sexual partner was older $(67 \%$ versus $34 \%$; $p<0.01$ ) while a significantly higher proportion of male than female respondents reported that the first sexual partner was younger or of the same age (Table 5).

The desire among adolescents to explore their sexuality is also evident among respondents who had never had sex. More than eight-in-ten (88\%) reported that they intend to have sex in future with no significant difference between female and male respondents ( $86 \%$ versus $91 \%$; $\mathrm{p}=0.27)$. However, about three-in-four $(76 \%)$ of respondents who had never had sex reported that they intend to wait until marriage before having sex (Figure 4). Again, there is no significant difference between female and male respondents reporting an intention to wait until marriage before having sex.

Figure 4: Distribution of respondents who have never had sex by intentions of having sex in future

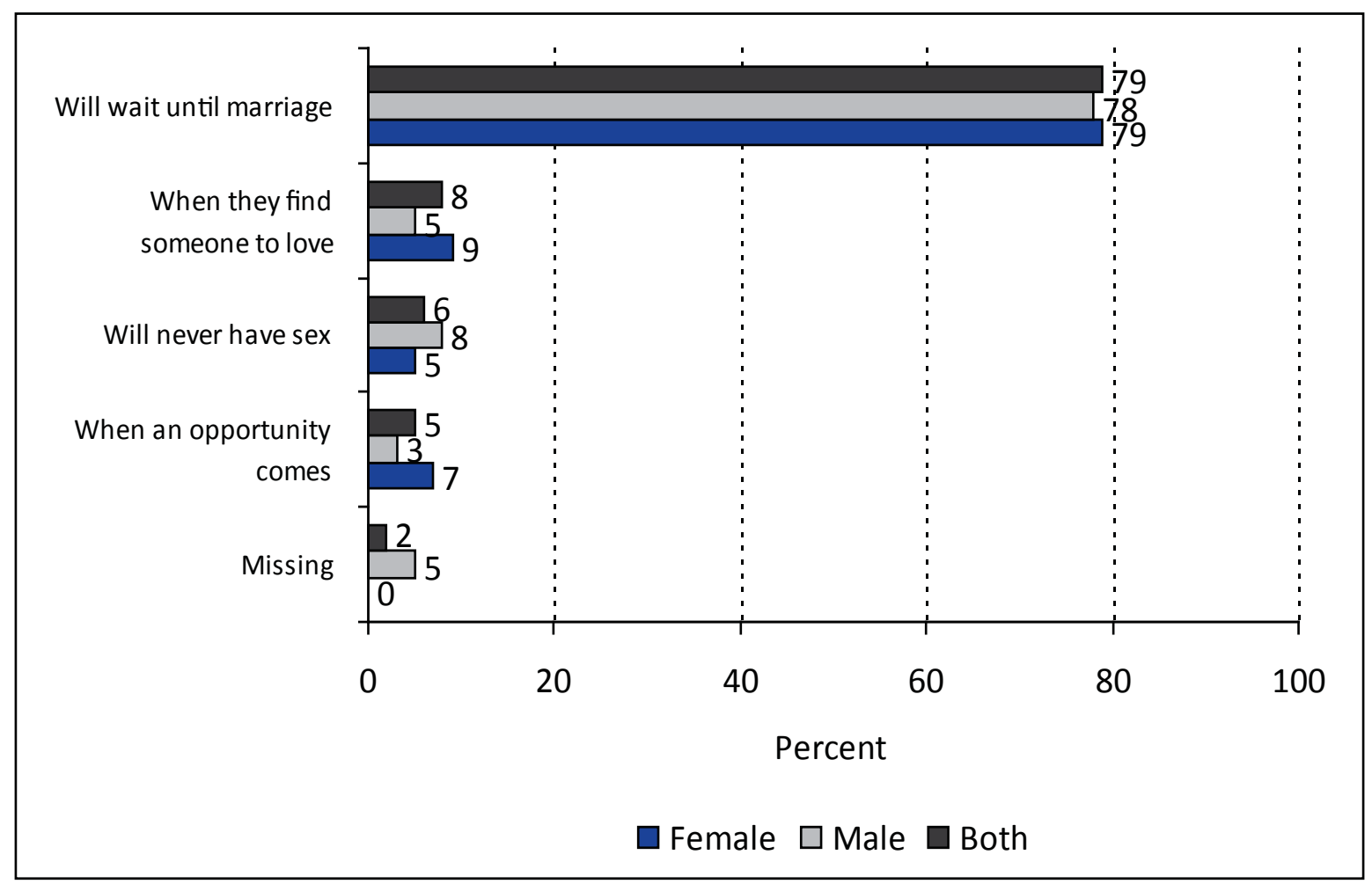

Respondents were further asked whether they felt that someone living with HIV should have sexual intercourse; more than half $(54 \%)$ felt so (56\% of female and $51 \%$ of male respondents; $\mathrm{p}=0.30$ ). More than half ( $55 \%$ ) of those who felt that someone living with HIV should have sex were of the view that this should only be after 
marriage with no significant difference between female and male respondents (Figure 5). In addition, about one-in-five (21\%) felt that a boy or girl living with HIV can start having sex any time $(17 \%$ of female and $29 \%$ of male respondents; $\mathrm{p}<0.05)$.

Figure 5: Distribution of respondents by perceived appropriate time for an HIV-positive boy or girl to start having sex

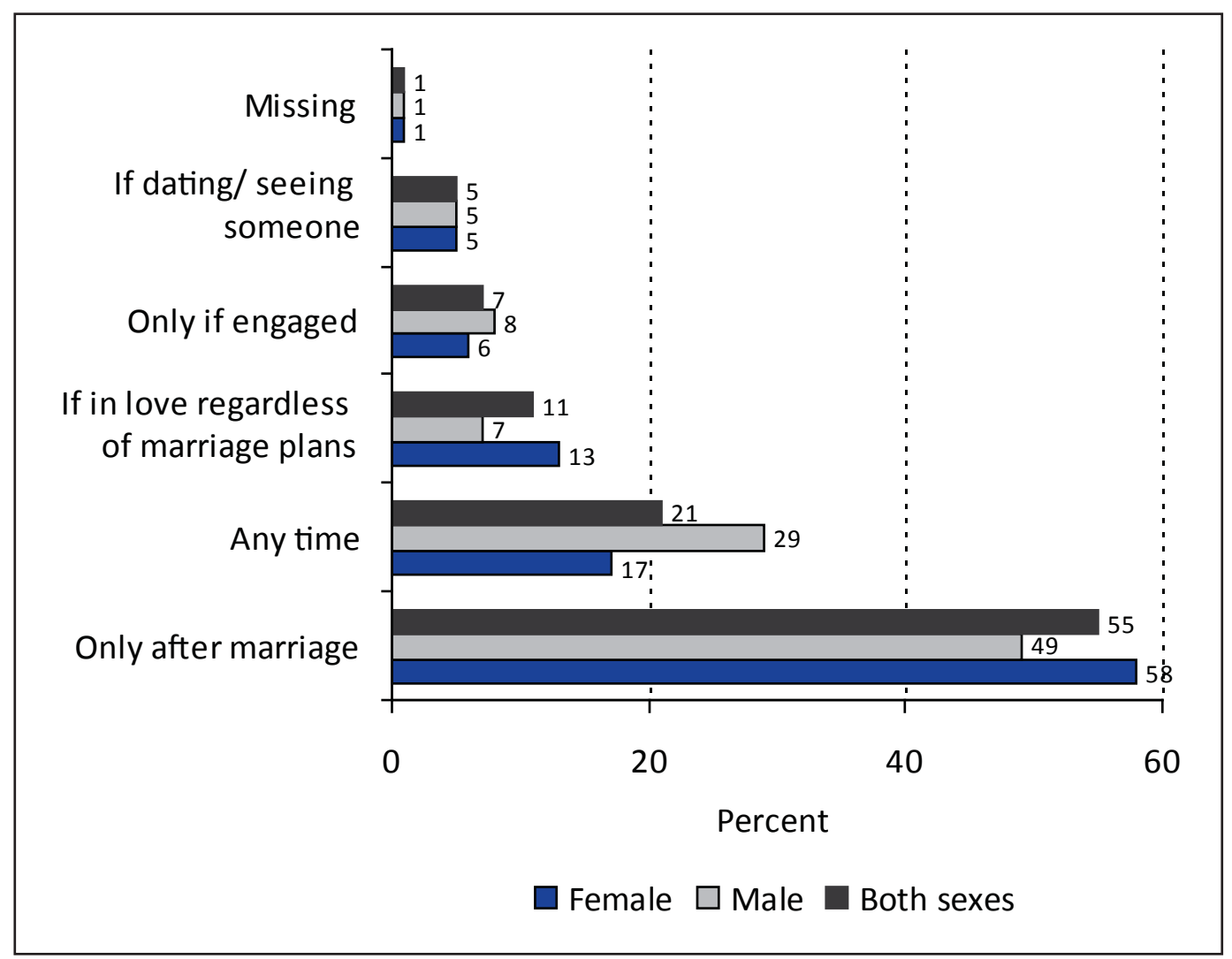

\section{HIV sero-status disclosure}

Respondents who were in a relationship were asked whether they had disclosed their HIV sero-status to their partners. About two-in-three (67\%) had disclosed to their partners their sero-status (Table 6). A similar proportion knew the HIV status of the partner. Although not statistically significant, a higher proportion of female than male respondents had disclosed their sero-status to their partners while a higher proportion of male than female respondents knew the HIV status of the partner. Among those who knew the HIV status of the partner, nearly half (46\%) were in discordant relationships (HIV-negative partner) while slightly more than half $(53 \%)$ were in concordant relationships (Table 6). A higher proportion of male than female respondents reported being in discordant relationships while a higher proportion of female than male respondents reported being in concordant relationships. The differences are, however, not statistically significant. 
Besides disclosing their HIV status to their partners, all respondents were asked who they had talked to about their sero-status. Eight-in-ten $(80 \%)$ had talked to the service provider/ counselor ( $83 \%$ of female and $74 \%$ of male respondents; $\mathrm{p}<0.05$ ). A similar proportion $(81 \%)$ reported talking to family member or close relative with no significant difference between female and male respondents (Table 6) while slightly more than one-in-three (38\%) reported talking to friends $(38 \%$ of female and $39 \%$ of male respondents; $\mathrm{p}=0.83$ ).

Table 6: Distribution of respondents by HIV sero-status disclosure

\begin{tabular}{|c|c|c|c|}
\hline Disclosure indicators & $\begin{array}{r}\text { Female } \\
(\%)\end{array}$ & $\begin{array}{r}\text { Male } \\
(\%)\end{array}$ & $\begin{array}{r}\text { Both sexes } \\
(\%)\end{array}$ \\
\hline Ever talked with partner about own status ${ }^{a}$ & 70 & 63 & 67 \\
\hline Knows HIV status of partner ${ }^{a}$ & 65 & 70 & 67 \\
\hline Partner's HIV status & $(\mathrm{N}=58)$ & $(\mathrm{N}=30)$ & $(\mathrm{N}=88)$ \\
\hline HIV-positive & 59 & 43 & 53 \\
\hline HIV-negative & 40 & 57 & 46 \\
\hline Missing & 2 & 0 & 1 \\
\hline Other persons talked to about status ${ }^{b}$ & $(\mathrm{~N}=288)$ & $(\mathrm{N}=167)$ & $(\mathrm{N}=455)$ \\
\hline Service provider/ counselor & 83 & $74^{*}$ & 80 \\
\hline Teacher & 14 & 19 & 16 \\
\hline Religious leader & 15 & 18 & 16 \\
\hline Family member/ close relative & 81 & 80 & 81 \\
\hline Friends & 38 & 39 & 38 \\
\hline Neighbors & 15 & 12 & 14 \\
\hline Other & 6 & 7 & 6 \\
\hline
\end{tabular}

${ }^{a}$ Among those currently in relationships ( 89 female and 43 male respondents); ${ }^{b}$ Questions allowed for multiple responses, percentages do not therefore sum to 100; Differences between male and female respondents are significant at: ${ }^{*} \mathrm{p}<0.05 ;{ }^{*} \mathrm{p}<0.01$.

The focus group discussions and key informant interviews provide some insights about fears and challenges around sero-status disclosure among HIV-positive adolescents as exemplified by the following excerpts:

Before you talk to someone, you have to be really sure about this person that you are telling. You can tell your friend, who will tell another person and your secret will now be out in the open. So, you think that your friend is your confidant and can keep your secret, but she is the one who will go telling everyone what you have told her (19-year old female participant, No. 5, Coast FGD).

But as for me, I believe if it is someone you do not trust completely... there is no need disclosing your status to them because initially before you got the virus they treated you like a normal person... When they know they treat you like someone who has come from another planet now (19-year old female participant, No. 5, Rift Valley FGD).

One time I had a youth - a lady, she was planning to get married and she didn't tell the man she is HIV-positive... I was telling her that being rejected might be even worse especially when you get so emotionally involved and you are married, being rejected later on might be more painful than earlier on. So we talked and I gave her another appointment. She promised to, but I haven't seen her again (Key informant interview provider No. 5, Coast). 


\section{Knowledge of preventive and contraceptive methods}

With respect to knowledge of ways in which someone can get infected with HIV, respondents mostly mentioned having unprotected sex with an infected person, followed by the use of contaminated non-sterilized instruments, blood transfusion and accidents, and mother-to-child through pregnancy, delivery and breastfeeding (Table 7). There is no significant difference between female and male respondents mentioning these ways.

Table 7: Distribution of respondents by knowledge and awareness of preventive/ contraceptive methods

\begin{tabular}{|c|c|c|c|}
\hline Knowledge/ awareness indicators & $\begin{array}{r}\text { Female } \\
(\%)\end{array}$ & $\begin{array}{r}\text { Male } \\
(\%)\end{array}$ & $\begin{array}{r}\text { Both sexes } \\
(\%)\end{array}$ \\
\hline Ways of getting infected with HIV & $(\mathrm{N}=288)$ & $(\mathrm{N}=167)$ & $(\mathrm{N}=455)$ \\
\hline Unprotected sex with infected person & 90 & 90 & 90 \\
\hline Using non-sterilized instruments & 69 & 76 & 71 \\
\hline Blood transfusion/ accidents & 43 & 49 & 45 \\
\hline Mother-to-child & 35 & 35 & 35 \\
\hline Kissing an infected person & 7 & 10 & 8 \\
\hline Sharing sharp objects & 2 & $7^{*}$ & 4 \\
\hline Other & 11 & 10 & 11 \\
\hline Ways of preventing re-infection ${ }^{a}$ & $(\mathrm{~N}=288)$ & $(\mathrm{N}=167)$ & $(N=455)$ \\
\hline Abstinence & 45 & $58^{*}$ & 50 \\
\hline Using condoms & 54 & 53 & 54 \\
\hline Not sharing sharp instruments & 22 & $31^{*}$ & 25 \\
\hline Taking/ adhering to ARVs & 3 & 4 & 3 \\
\hline Being faithful to one partner & 4 & 6 & 5 \\
\hline Other & 12 & 15 & 13 \\
\hline Knows any contraceptive methods & 77 & 78 & 77 \\
\hline Methods known ${ }^{a}$ & $(N=222)$ & $(\mathrm{N}=130)$ & $(N=352)$ \\
\hline Pill & 63 & $45^{* *}$ & 57 \\
\hline Injectables & 51 & $26^{* *}$ & 42 \\
\hline Condoms & 78 & 85 & 80 \\
\hline IUCD/ coil & 13 & $4^{* *}$ & 9 \\
\hline Norplant/ implants & 9 & 2 & 7 \\
\hline Emergency pill & 13 & 14 & 13 \\
\hline Withdrawal & 1 & 2 & 1 \\
\hline Abstinence & 21 & 29 & 24 \\
\hline Rhythm & 8 & 9 & 8 \\
\hline Other & 10 & 9 & 9 \\
\hline Knows any source of contraceptives ${ }^{b}$ & 86 & 82 & 84 \\
\hline \multicolumn{4}{|c|}{$\begin{array}{l}\text { aQuestions allowed for multiple responses, percentages do not therefore sum to } 100 \text {; }{ }^{\mathrm{b}} \mathrm{Among} \\
\text { those who knew a method ( } 211 \text { female and } 124 \text { male respondents); IUCD- intrauterine } \\
\text { contraceptive device; ARVs- antiretroviral drugs; Differences between male and female } \\
\text { respondents are significant at: } \mathrm{p}<0.05 \text {; }{ }^{* *}<<0.01 \text {. }\end{array}$} \\
\hline
\end{tabular}

Both abstinence and use of condoms were the most commonly cited ways of avoiding re-infection with another strain of HIV while one-in-four (25\%) mentioned avoiding sharing sharp instruments. A significantly higher proportion of male than female respondents mentioned abstinence and avoiding sharing sharp objects (Table 7). More than three-in-four (77\%) knew of a contraceptive method with no significant difference between female and male respondents. The most commonly known methods are condoms, pills and injectables. As expected, a significantly higher proportion of female than male respondents reported knowledge of the pills, injectables, and intra-uterine contraceptive device. Among those who knew a 
method, slightly more than eight-in-ten (84\%) reported knowing a place where the methods can be obtained with no significant difference between female and male respondents.

\section{Use and sources of contraceptive methods}

Knowledge of contraceptives among adolescents living with HIV is high, but actual use is low. This is similar to the patterns observed among adolescents in the general population based on findings from the Kenya Demographic and Health Surveys. Among those who had consensual first sex, only about one-in-four $(23 \%)$ used a preventive method at first sex with no significant difference between female and male respondents (Table 8 ). In addition, among those who had ever had sex, only $57 \%$ had ever used a contraceptive method while $46 \%$ reported currently using a method. Again, there is no significant difference between female and male respondents with respect to ever or current use of contraceptives.

Those currently using contraceptives mostly obtained the methods from the HIV/ AIDS and voluntary counseling and testing (VCT) centers (54\%), shop (29\%), and pharmacy (21\%); (Table 8$)$. A significantly higher proportion of male than female respondents reported obtaining the methods from shops, pharmacy, and friends. In addition, the most preferred source of contraceptives for all respondents if they were to use the methods is the HIV/AIDS VCT centers (33\%) followed by pharmacies $(17 \%)$.

Table 8: Distribution of respondents by use and source of contraceptive methods

\begin{tabular}{|c|c|c|c|}
\hline Use and source of method & $\begin{array}{r}\text { Female } \\
(\%)\end{array}$ & $\begin{array}{r}\text { Male } \\
(\%) \\
\end{array}$ & $\begin{array}{r}\text { Both sexes } \\
(\%)\end{array}$ \\
\hline Used a preventive method at first sex ${ }^{a}$ & 25 & 19 & 23 \\
\hline Ever used a contraceptive method ${ }^{b}$ & 58 & 55 & 57 \\
\hline Currently using a method ${ }^{b}$ & 48 & 42 & 46 \\
\hline Methods currently using with partner & $(\mathrm{N}=83)$ & $(\mathrm{N}=31)$ & $(\mathrm{N}=114)$ \\
\hline Condom & 90 & 100 & 93 \\
\hline Pill & 10 & 3 & 8 \\
\hline Injectables & 19 & $0^{*}$ & 14 \\
\hline Implants & 2 & 0 & 2 \\
\hline Emergency pill & 2 & 0 & 2 \\
\hline Withdrawal & 0 & 3 & 1 \\
\hline Source of method ${ }^{c}$ & $(\mathrm{~N}=83)$ & $(\mathrm{N}=31)$ & $(\mathrm{N}=114)$ \\
\hline Shop & 18 & $58^{* *}$ & 29 \\
\hline Pharmacy & 16 & $36^{*}$ & 21 \\
\hline HIV/AIDS/VCT centre & 53 & 55 & 54 \\
\hline Other health facility & 16 & 19 & 17 \\
\hline Friends & 5 & $16^{*}$ & 8 \\
\hline Other & 6 & 7 & 6 \\
\hline $\begin{array}{l}\text { Preferred source of contraceptives }^{c} \\
\text { HIV/AIDS/VCT centre } \\
\text { Family planning clinic } \\
\text { Any health facility } \\
\text { Youth clinic/ centre } \\
\text { Pharmacy } \\
\text { Other } \\
\text { Don't know } \\
\text { Missing } \\
\end{array}$ & $\begin{array}{r}(\mathrm{N}=288) \\
33 \\
16 \\
13 \\
4 \\
13 \\
6 \\
6 \\
10 \\
\end{array}$ & $\begin{array}{r}(\mathrm{N}=167) \\
33 \\
7^{* *} \\
11 \\
6 \\
23^{* *} \\
6 \\
8 \\
7 \\
\end{array}$ & $\begin{array}{r}(\mathrm{N}=455) \\
33 \\
12 \\
12 \\
4 \\
17 \\
6 \\
7 \\
9\end{array}$ \\
\hline \multicolumn{4}{|c|}{$\begin{array}{l}{ }^{a} \text { Among those whose first sexual experience was not forced/ rape (149 female and } 68 \text { male } \\
\text { respondents); }{ }^{b} \text { Among those who have ever had sex (173 female and } 74 \text { male respondents); } \\
\text { IUCD- intrauterine contraceptive device; }{ }^{\text {IU }} \text { Questions allowed for multiple responses, percentages } \\
\text { do not therefore sum to 100; Differences between male and female respondents are significant at: } \\
{ }^{*} p<0.05 ;{ }^{* *} p<0.01 \text {. }\end{array}$} \\
\hline
\end{tabular}


Condoms are the most commonly used methods among current users of contraceptive; nearly all respondents (93\%) reported using condoms (Table 8). The most common reason for using condoms was to prevent re-infection with another strain of HIV, followed by preventing HIV/STIs and pregnancy in that order (Figure 6). There is no significant difference between female and male respondents with respect to using condoms for preventing re-infection or pregnancy. However, a significantly higher proportion of male than female respondents reported using condoms to prevent HIV/STIs. Only a small proportion of respondents (19\%) reported using condoms for dual protection (prevention of pregnancy and HIV/STIs).

Figure 6: Distribution of respondents currently using a condom by the reasons for use

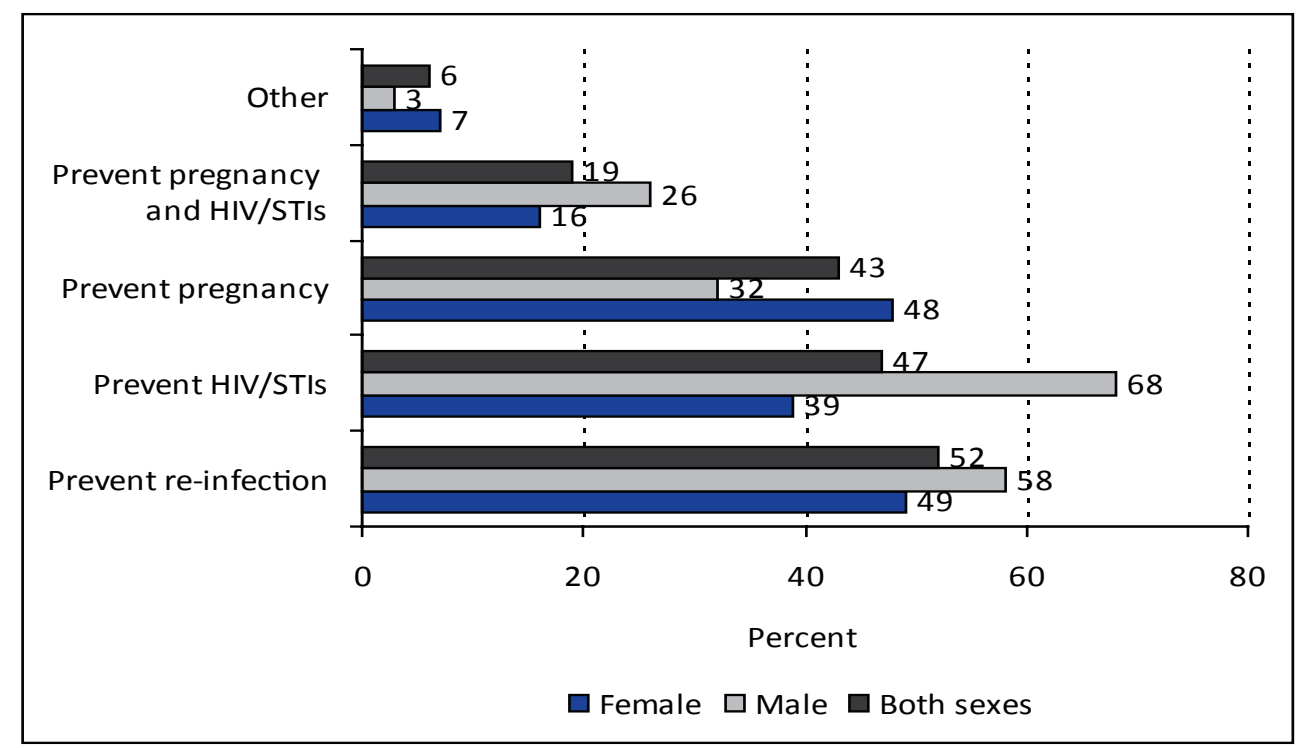

Respondents currently using a method were asked about the frequency of use. Threein-five $(60 \%)$ reported always using contraceptives with no significant difference between female and male respondents (Figure 7).

Figure 7: Distribution of respondents who are currently using contraceptives by the frequency of use

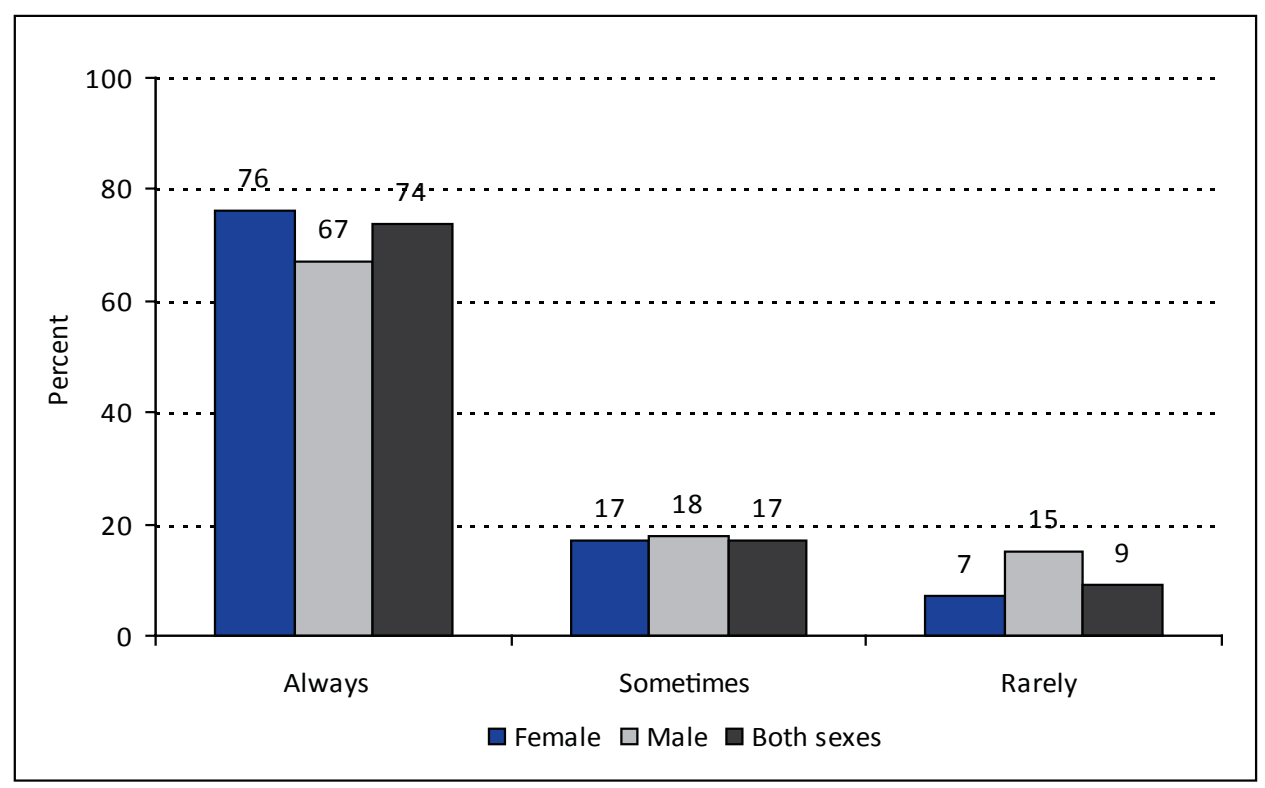




\section{Pregnancy and childbearing experiences and intentions}

Nearly two-in-three (65\%) of female respondents who had ever had sex have been pregnant while nearly one-in-five (23\%) of male respondents who had ever had sex have made someone pregnant (Table 9). The average age at first pregnancy among female respondents is 16 years. One-in-five (20\%) of those who have ever been pregnant or made someone pregnant had done so more than once (19\% of female and $30 \%$ of male respondents; $p=0.29$ ). In addition, nearly one-in-five (19\%) of the female respondents who have been pregnant and slightly more than half (53\%) of the male respondents who have made someone pregnant reported no living child.

Table 9: Distribution of respondents by pregnancy and childbearing experiences and intentions

\begin{tabular}{|c|c|c|c|}
\hline Pregnancy and childbearing indicators & Female & Male & Both sexes \\
\hline Ever been pregnant/ impregnated someone (\%) ${ }^{a}$ & 65 & $23^{* *}$ & 52 \\
\hline $\begin{array}{l}\text { Number of times pregnant/ impregnated someone (\%) } \\
1 \\
2 \\
3 \\
4 \\
\text { Missing }\end{array}$ & $\begin{array}{r}(\mathrm{N}=112) \\
81 \\
16 \\
2 \\
1 \\
0\end{array}$ & $\begin{array}{r}(\mathrm{N}=17) \\
65 \\
18 \\
6 \\
6 \\
6^{* *} \\
\end{array}$ & $\begin{array}{r}(\mathrm{N}=129) \\
79 \\
16 \\
2 \\
2 \\
1\end{array}$ \\
\hline $\begin{array}{l}\text { Number of living children (\%) } \\
0 \\
1 \\
2 \\
3 \\
4\end{array}$ & $\begin{array}{r}(\mathrm{N}=112) \\
19 \\
72 \\
8 \\
1 \\
0\end{array}$ & $\begin{array}{r}(\mathrm{N}=17) \\
53^{* *} \\
18^{* *} \\
24^{*} \\
0 \\
6^{* *}\end{array}$ & $\begin{array}{r}(\mathrm{N}=129) \\
23 \\
65 \\
10 \\
1 \\
1\end{array}$ \\
\hline $\begin{array}{l}\text { Intends to have children in future (\%) } \\
\text { Yes } \\
\text { No }\end{array}$ & $\begin{array}{r}(\mathrm{N}=288) \\
71 \\
29\end{array}$ & $\begin{array}{r}(\mathrm{N}=167) \\
88^{* *} \\
12^{* *}\end{array}$ & $\begin{array}{r}(\mathrm{N}=455) \\
77 \\
23\end{array}$ \\
\hline $\begin{array}{l}\text { Intended timing of future childbirth (\%) } \\
\text { Very soon } \\
\text { Later in life } \\
\text { Not decided } \\
\text { Missing } \\
\end{array}$ & $\begin{array}{r}(\mathrm{N}=205) \\
4 \\
90 \\
5 \\
0\end{array}$ & $\begin{array}{r}(\mathrm{N}=147) \\
6 \\
84 \\
9 \\
1\end{array}$ & $\begin{array}{r}(\mathrm{N}=352) \\
5 \\
88 \\
7 \\
0\end{array}$ \\
\hline $\begin{array}{l}\text { Mean and median number of intended children } \\
\text { Mean } \\
\text { Median }\end{array}$ & $\begin{array}{r}(\mathrm{N}=195) \\
2 \\
2\end{array}$ & $\begin{array}{r}(\mathrm{N}=135) \\
3^{* *} \\
3\end{array}$ & $\begin{array}{r}(N=330) \\
3 \\
2\end{array}$ \\
\hline
\end{tabular}

aAmong respondents who have ever had sex (173 female and 74 male respondents); Differences between male and female respondents are significant at: ${ }^{*} \mathrm{p}<0.05 ;{ }^{* *} \mathrm{p}<0.01$.

With respect to future childbearing intentions, more than three-in-four (77\%) of all respondents intend to have children in future. A significantly higher proportion of male than female respondents reported such intention (Table 9). Among those who intend to have children in future, more than four-in-five (88\%) intend to have children later in life. Male respondents, on average, intend to have more children than their female counterparts (3 versus $2 ; \mathrm{p}<0.01$ ).

\section{Pregnancy outcomes and use of health services}

The total number of pregnancies reported by female respondents who have ever been pregnant was 137 , majority $(72 \%)$ of which were unintended (Table 10). There is no significant difference between study sites with respect to the proportion of unintended pregnancies. Boyfriends were responsible for slightly over six-inten $(63 \%)$ while husbands were responsible for nearly three-in-ten $(29 \%)$ of the pregnancies. 
Overall utilization of antenatal care services was high-- for $77 \%$ of the pregnancies (Table 10). Although not statistically significant, the proportion of pregnancies for which antenatal care services were received was higher in Rift Valley than in Coast province $(84 \%$ versus $71 \%$; $\mathrm{p}=0.07)$. Mothers made an average of five antenatal care visits. It is worth noting, however, that whereas mothers received antenatal care services for more than three-in-four of the pregnancies, they received services for prevention of mother-to-child transmission (PMTCT) of HIV for only 56\% of the pregnancies (Table 10). In-depth interviews with ever pregnant adolescent girls suggest that this could be partly attributable to the availability and quality of services as exemplified by the following excerpts:

Respondent: They are, right now most of the people are complaining about there because a doctor may come in then leave, then he takes long to come back, I don't know if they go for breaks or what. When he comes to attend to you, you have been waiting for long you are tired and hungry. I don't like that service.

When he comes he says, you what problem do you have? If you explain to him he does not carry on tests on you. He only prescribes for you medicine and you go to collect it. And sometimes you do not have money for the medicine. So you do not get it (In-depth interview No. 1, 19-year old, Coast)

$* * * * * * * * * * * * * * * * * * * * * * * * * * * * * * * * * * * * * * * * * * * * * * * * * * * * * * * * * * * * * * * * * * * * * * * * * * * * * *$

Interviewer: Did you ever attend antenatal clinic when you were pregnant?

Respondent: I went but I was not tested.

Interviewer: But did they do any physical examination on you?

Respondent: Yes, I was examined and I was given vitamin tablets which I took. After that I gave birth.

Interviewer: So, was it a requirement to get tested for HIV or was it not a requirement to get tested when you went to the clinic while pregnant?

Respondent: I was not told anything about it but I did not see them testing anybody.

Interviewer: So, you did not use any PMTCT services when you were pregnant?

Respondent: I did not because I did not know about them and I was not told anything about them when I went to the hospital.

Interviewer: Was it a big hospital or a small one?

Respondent: It is just a small center (In-depth interview No. 3, 19-year old, Rift Valley). 
Table 10: Distribution of pregnancies by outcomes and use of maternal and child health services according to study site

\begin{tabular}{|c|c|c|c|}
\hline Indicators & Rift Valley & Coast & Both sites \\
\hline Percent of pregnancies unintended ${ }^{a}$ & 73 & 70 & 72 \\
\hline Relationship to person responsible for pregnancy (\%) & $(\mathrm{N}=64)$ & $(N=73)$ & $(\mathrm{N}=137)$ \\
\hline Boyfriend & 66 & 60 & 63 \\
\hline Fiancé & 2 & 3 & \\
\hline Husband & 25 & 33 & 29 \\
\hline Acquaintance & 3 & 3 & \\
\hline Other & 5 & 1 & \\
\hline Received antenatal care (\%) ${ }^{a}$ & 84 & 71 & 77 \\
\hline Mean and median number ANC visits & $(\mathrm{N}=47)$ & $(\mathrm{N}=47)$ & $(\mathrm{N}=94)$ \\
\hline $\begin{array}{l}\text { Mean } \\
\text { Median }\end{array}$ & & $\begin{array}{l}5 \\
5\end{array}$ & \\
\hline Received PMTCT services (\%) & 55 & 56 & 56 \\
\hline Mean and median number РМТСТ visits & $(\mathrm{N}=29)$ & $(N=39)$ & $(\mathrm{N}=68)$ \\
\hline Mean & 3 & 3 & \\
\hline Median & 3 & 3 & \\
\hline Delivered at health facility $(\%)^{b}$ & 71 & 68 & 69 \\
\hline Assisted by doctor/ nurse (\%) & 74 & 65 & 69 \\
\hline Received post-natal care $(\%)^{b}$ & 77 & 69 & 73 \\
\hline Used family planning after delivery $(\%)^{b}$ & 48 & 46 & 47 \\
\hline Child tested for HIV $(\%)^{\mathrm{c}}$ & 78 & $93^{*}$ & 85 \\
\hline Respondent willing to share results (\%) ${ }^{d}$ & 100 & 98 & 99 \\
\hline HIV test results (\%) & $(\mathrm{N}=47)$ & $(N=52)$ & $(\mathrm{N}=99)$ \\
\hline HIV-positive & 11 & $27^{*}$ & 19 \\
\hline HIV-negative & 84 & $67^{*}$ & 76 \\
\hline Indeterminate & 0 & 4 & \\
\hline Don't know & 6 & 2 & \\
\hline Child is still alive (\%) ${ }^{\mathrm{c}}$ & 88 & 86 & 87 \\
\hline \multicolumn{4}{|c|}{$\begin{array}{l}\text { a Among all pregnancies (64 in Rift Valley and } 73 \text { in Coast); }{ }^{\mathrm{b}} \text { Among pregnancies that had ended } \\
\text { (61 in Rift Valley and } 68 \text { in Coast); }{ }^{\mathrm{c}} \text { Among pregnancies that resulted in live births (59 in Rift } \\
\text { Valley and } 57 \text { in Coast); }{ }^{\mathrm{d}} \text { Among live births that were tested for HIV ( } 46 \text { in Rift Valley and } 53 \\
\text { in Coast); ANC- antenatal care; PMTCT- prevention of mother-to-child transmission (of HIV); } \\
\text { Differences between study sites are significant at: }{ }^{*} \mathrm{p}<0.05 ;{ }^{* *} \mathrm{p}<0.01 \text {. }\end{array}$} \\
\hline
\end{tabular}

Slightly more than eight-in-ten (85\%) of the pregnancies resulted in a live birth $(92 \%$ in Rift Valley versus $78 \%$ in Coast province; $\mathrm{p}<0.05$ ) while respondents were still pregnant in $5 \%$ of the cases (Figure 8). Of the pregnancies that had ended, nearly seven-in-ten $(69 \%)$ were delivered at a health facility and mothers received assistance from a doctor or a nurse for a similar proportion of pregnancies. Mothers received post-natal care services for nearly three-in-four $(73 \%)$ of the pregnancies that had ended. However, the use of family planning methods after delivery was low (47\%).

For pregnancies that resulted in live births, infants were tested for HIV in $85 \%$ of the cases with a significantly higher proportion of infants from Coast than those from Rift Valley province having been tested for HIV (Table 10). In nearly all cases (99\%) where infants were tested, the mothers were willing to share the test results. Slightly more than seven-in-ten $(76 \%)$ of the infants that were tested were HIV-negative ( $84 \%$ in Rift Valley and $67 \%$ in Coast province; $\mathrm{p}<0.05$ ). In addition, slightly more than eight-in-ten $(87 \%)$ of the infants that were born alive were still surviving by the time of the survey. 
Figure 8: Distribution of pregnancies by outcomes

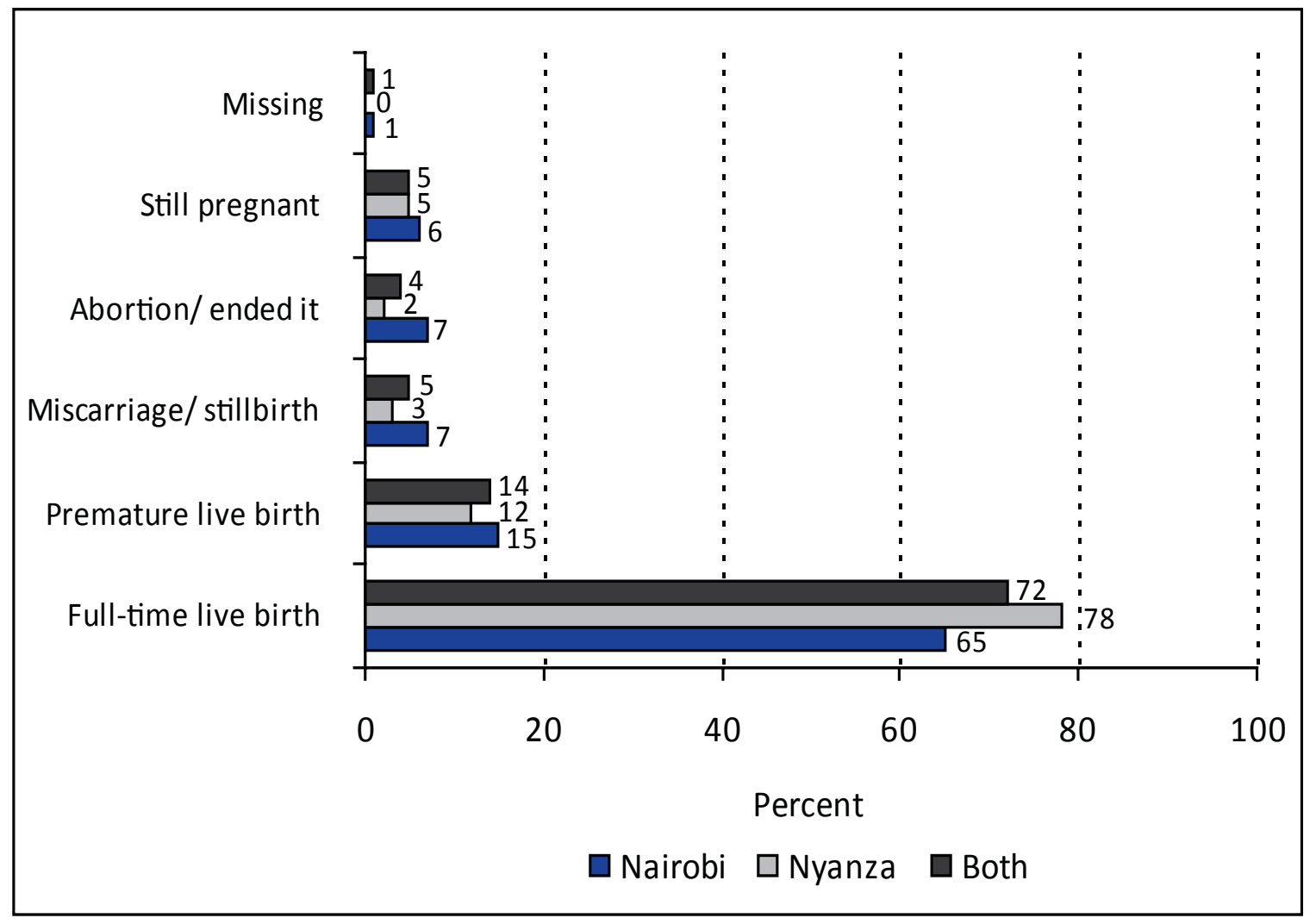

\section{Experiences of violence and self-esteem}

About three-in-ten (31\%) and 15\% of respondents reported experiencing physical and sexual abuse respectively with no significant difference between female and male respondents (Table 11). In $71 \%$ of the sexual abuse cases, the perpetrators were those familiar to the respondents, that is, relative, steady boy/ girlfriend, and friend or an acquaintance $(71 \%$ of female and $72 \%$ of male respondents who experienced sexual abuse; $p=0.93$ ). Among respondents who experienced physical abuse, $65 \%$ discussed the problem with someone while only 55\% of those who experienced sexual abuse discussed the problem with someone. Although not statistically significant, a higher proportion of female than male respondents who experienced either physical or sexual abuse reported discussing the problem with anyone. In both cases, the problem was mostly discussed with a family member followed by a close friend (Table 11). 
Table 11: Distribution of respondents by experiences of violence

\begin{tabular}{|c|c|c|c|}
\hline Indicators of violence & $\begin{array}{r}\text { Female } \\
(\%)\end{array}$ & $\begin{array}{r}\text { Male } \\
(\%) \\
\end{array}$ & $\begin{array}{r}\text { Both sexes } \\
(\%)\end{array}$ \\
\hline Ever been physically abused ${ }^{a}$ & 31 & 33 & 31 \\
\hline Discussed problem with anyone ${ }^{b}$ & 72 & 56 & 65 \\
\hline Person discussed problem with ${ }^{c}$ & $(\mathrm{~N}=63)$ & $(\mathrm{N}=31)$ & $(\mathrm{N}=94)$ \\
\hline Family member & 59 & 71 & 63 \\
\hline Close friend & 22 & 26 & 23 \\
\hline Teacher & 0 & $7^{*}$ & 2 \\
\hline Health provider/ counselor & 8 & 10 & 9 \\
\hline Religious leader & 2 & 0 & 1 \\
\hline Other & 22 & 16 & 20 \\
\hline Ever been sexually abused ${ }^{a}$ & 16 & 13 & 15 \\
\hline Perpetrator of sexual abuse & $(\mathrm{N}=45)$ & $(\mathrm{N}=21)$ & $(\mathrm{N}=66)$ \\
\hline Relative & 9 & 10 & 9 \\
\hline Steady boyfriend/ girlfriend & 31 & 10 & 24 \\
\hline Friend/acquaintance & 31 & 52 & 38 \\
\hline Stranger & 24 & 24 & 24 \\
\hline Missing & 4 & 5 & 5 \\
\hline Discussed problem with anyone & 58 & 48 & 55 \\
\hline Person discussed problem with ${ }^{c}$ & $(\mathrm{~N}=26)$ & $(\mathrm{N}=10)$ & $(\mathrm{N}=36)$ \\
\hline Family member & 58 & 50 & 56 \\
\hline Close friend & 31 & 40 & 33 \\
\hline Teacher & 0 & 10 & 3 \\
\hline Health provider/ counselor & 4 & 10 & 6 \\
\hline Religious leader & 0 & 10 & 3 \\
\hline Other & 19 & 20 & 19 \\
\hline \multicolumn{4}{|c|}{$\begin{array}{l}\text { aAmong all respondents ( } 288 \text { female and } 167 \text { male respondents); }{ }^{b} \text { Among respondents that had } \\
\text { been physically abused ( } 88 \text { female and } 55 \text { male respondents); }{ }^{\circ} \text { Questions allowed for multiple } \\
\text { responses, percentages do not therefore sum to } 100 \text {; Differences between male and female } \\
\text { respondents are significant at: }{ }^{*} p<0.05 ;{ }^{* *} p<0.01 \text {. }\end{array}$} \\
\hline
\end{tabular}

Respondents were also asked about whether they worry about various issues in life including social acceptance, body looks, their HIV sero-status, and sexual and reproductive health issues. Less than half (43\%) are worried about being HIVpositive with no significant difference between female and male respondents (Table 12). Rather, they are mostly worried about infecting someone else with HIV (85\%), becoming or making someone pregnant $(66 \%)$, disclosing their HIV status to friends (64\%), people finding out that they are living with HIV $(64 \%)$, being forced to do sexual things that they do not want (63\%), and having sex (57\%). A significantly higher proportion of female than male respondents were worried about having sex, being forced to do sexual things that they do not want, and being mistreated or rejected by friends. In contrast, a significantly higher proportion of male than female respondents were worried about infecting someone else with HIV (Table 12). 
Table 12: Percent distribution of respondents who are worried about various aspects of life

\begin{tabular}{|l|r|r|r|}
\hline Percentage of respondents worried about & $\begin{array}{r}\text { Female } \\
\text { (N=288) } \\
\text { \% }\end{array}$ & $\begin{array}{r}\text { Male } \\
\text { (N=167) } \\
\text { \% }\end{array}$ & $\begin{array}{r}\text { Both sexes } \\
\text { (N=455) } \\
\text { \% }\end{array}$ \\
\hline Being mistreated/ rejected by friends & 43 & $33^{*}$ & 39 \\
Being unable to find boyfriend/ girlfriend/ partner & 31 & 29 & 30 \\
Being dumped by boyfriend/ girlfriend/ partner & 46 & 41 & 44 \\
Their looks & 25 & 28 & 26 \\
Being HIV-positive & 43 & 43 & 43 \\
Disclosing their HIV status to friends & 62 & 68 & 64 \\
Becoming/ making someone pregnant & 64 & 68 & 66 \\
People finding out they are living with HIV & 61 & 68 & 64 \\
Infecting someone else with HIV & 82 & 90 & 85 \\
Body not developing as fast as their friends' & 40 & 47 & 43 \\
Having sex & 60 & $50^{*}$ & 57 \\
Being forced to do sexual things they don't want & 70 & $52^{* *}$ & 63 \\
\hline Differences between male and female respondents are significant at: ${ }^{*} \mathrm{p}<0.05 ;{ }^{* * *} \mathrm{p}<0.01$. & \\
\hline
\end{tabular}

Focus group discussions further support the contention that young people living with HIV worry more about pregnancy and infecting others than with their own HIV sero-status as shown by the following excerpts:

Personally, I would like to get somebody who is just like me. But my biggest worry is about getting pregnant and what the HIV status of that baby will be. Currently there is a research which says that if you follow all the regulations, there is a small chance that the baby will be positive. Getting pregnant and having that small chance that the baby might be positive worries me. I would like to have a baby who is HIV-negative (19-year old female participant, No. 1, Coast FGD).

Another problem would be when I have sex with a girl... I will be worried because I do not know whether I may have infected her or whether I have re-infected myself with more viruses (18-year old male participant, No. 4, Rift Valley FGD).

And giving birth. You expect that maybe the girl you will love, maybe you will love one another and by bad luck she does not have the virus. Obviously you will want children; that is normally stressing. You see now this daughter of someone, you will take her and infect her with something which she does not know where I got it from because you want a baby (19-year old male participant, No. 3, Coast FGD).

\section{Summary of findings}

The objective of this study was to assess the sexual and reproductive health needs of adolescents living with HIV in Kenya with a view to identify and developi interventions that integrate these needs within the existing HIV/AIDS treatment, care and support programs in the country. The major findings are as follows:

- As expected, many of the adolescents living with HIV are vulnerable: Most of them have lost one or both parents while many are out of school largely because of lack of school fees or materials. Most of those who are out of school 
did not go beyond primary level education which means that they have limited opportunities for advancing in their careers. In terms of schooling, more HIVpositive female than male respondents are disadvantaged. Whereas this also applies to the general population, being HIV-positive compounds further the situation for these female adolescents.

- There are programmatic gaps in addressing the sexual and reproductive health needs of HIV-positive adolescents: Key informant interviews with service providers/ counselors show that similar to the situation in Uganda, this is mostly due to service orientation, lack of provider training in SRH counseling for HIV-positive adolescents, inadequate financial and human resources, and the difficulty of dealing with adolescent sexuality in general.

- Most HIV-positive adolescents talk to service providers/ counselors more than to parents/guardians about sexual and reproductive health issues: This can largely be attributed to the social and cultural norms that guide discussion of SRH issues between adolescents and adults, especially parents/guardians, in much of subSaharan Africa. Qualitative interviews also showed that most parents/ guardians lack the skills for discussing SRH issues with the adolescents as they tend to issue warning messages rather than providing practical information, guidance and support. Moreover, although most HIV-positive adolescents talked to service providers/ counselors, one-in-four of the adolescents still found it difficult talking to the providers about issues that are important to them. This suggests that some of the adolescents might be getting such information from unqualified sources which, as interviews with key informants suggest, might not always be correct, or they could be getting no information at all.

- Few of the HIV-positive adolescents belong to any support group: Only about four-in-ten of the HIV-positive adolescents reported belonging to a support group. This suggests that many do not access the kind of support services that the groups offer which include peer support, life skills training, and psychosocial support. It also implies that many might not benefit from critical sexual and reproductive health information for HIV-positive young people which can be channeled through the groups.

- Most of the HIV-positive adolescents have ever been in a relationship; many are in or intend to be involved in relationships: Two-in-three of the HIV-positive adolescents have been in a relationship and about four-in-ten of these (i.e. those who have been in a relationship) were still in a relationship by the time of the survey. About eight-in-ten of those who have never been in a relationship intend to be involved in relationships in future while among those who are not married or living with someone, a similar proportion intend to marry in future.

- Nearly half of the HIV-positive adolescents desire to have sex; many have had sex or intend to have sex in future: Focus group discussions show that many of them felt this is natural. More than half felt that someone living with HIV should have sex and a similar proportion have had sex. Among those who have had sex, about two-thirds had consensual first sex. Besides, among those who have never had sex, nearly nine-in-ten intend to have sex in future with most (three-in-four) of them planning to wait until marriage before having sex. 
- Although knowledge of contraceptives is high, actual use of the methods is low: Nearly eight-in-ten of the adolescents surveyed know of a contraceptive method and a similar proportion know of a place to get a method. Nonetheless, only about two-in-ten of those who had consensual first sex used a preventive method that first time. In addition, among those who have ever had sex, slightly more than half have ever used a method while less than half reported current use of a method.

- There is high rate of unintended pregnancies among HIV-positive adolescent girls: About two-thirds of sexually active HIV-positive adolescent girls have been pregnant. About one-in-five of these have been pregnant more than once while about seven-in-ten of all the pregnancies are unintended. Respondents' boyfriends were responsible for about six-in-ten of the pregnancies.

- Although most of the HIV-positive adolescents intend to have children in future, the majority desire to delay childbearing: Nearly eight-in-ten of the adolescents surveyed intend to have children in future with a significantly higher proportion of male than female respondents expressing such desire. However, nearly ninein-ten of those who intend to have children in future would like to do so later on in life.

- There is low use of PMTCT compared to antenatal care services among pregnant HIV-positive adolescent girls: Although PMTCT should be part of antenatal care for HIV-positive mothers, the proportion of pregnancies for which mothers received antenatal care is higher than that for which they received PMTCT services. In-depth interviews with a subset of ever pregnant HIV-positive adolescent girls who did not receive PMTCT services suggest that this could be partly because of availability and quality of services offered.

- HIV-positive adolescents are mostly worried about infecting others, pregnancy, sero-status disclosure, and sexual violence: More than four-in-five are worried about infecting someone with HIV, two-thirds are worried about pregnancy, while almost a similar proportion are worried about sero-status disclosure and sexual violence. This is further supported by findings from the focus group discussions and key informant interviews with service providers/ counselors.

\section{Programmatic implications}

The study findings highlight a number of areas that the existing HIV/AIDS treatment, care and support programs in the country need to strengthen in order to provide HIV-positive young people with appropriate information and services. These include:

- The need to strengthen the provision of information and services on family planning and HIV prevention: First, most HIV-positive young people engage or desire to engage in sex just like other adolescents. Second, although most of them know of a contraceptive method, actual use is low. It is therefore not surprising 
that the rate of unintended pregnancies among sexually active HIV-positive adolescent girls is high. Moreover, there is the potential for further spread of HIV, especially if sex occurs with discordant partners. At the same time, most HIVpositive adolescents are worried about infecting others with HIV and pregnancy. All these underscore the need for HIV/AIDS treatment, care and support programs to assess the contraceptive and preventive service needs of adolescents living with HIV, and to strengthen the provision of appropriate information and services to this group of clients.

- Programs need to ensure effective provision of PMTCT services for HIV-positive adolescents during pregnancy: PMTCT services should be an integral component of antenatal care for HIV-positive mothers to reduce the likelihood of vertical transmission of HIV. However, the fact that a substantial proportion of pregnant HIV-positive adolescents received antenatal but not PMTCT services implies that there are still gaps in the provision of these services. HIV/AIDS programs therefore need to identify HIV-positive adolescent girls who are pregnant, provide support including information on and referral for the full range of antenatal care and PMTCT services, and put in place follow-up mechanisms to ensure that they receive the services.

- There is need to update the existing counseling and support packages to include sexual and reproductive health information and services: This will equip service providers/ counselors with a tool that they can use: 1) as a checklist to determine the relevant SRH items to discuss with HIV-positive adolescents during counseling sessions; and 2) to systematically assess the SRH information and service needs of HIV-positive adolescents with a view to addressing such needs in a timely manner or making appropriate referral.

- Updating the counseling and support packages need to be accompanied with training/ re-orienting service providers/ counselors: This will enhance provider capacity to handle the additional tasks and thus enable them to carry out their work effectively. Programs will also need to ensure that the updated package is part of the curriculum for pre-service training of providers/ counselors.

- There is need to put in place mechanisms for involving parents/ guardians in discussion of sexual and reproductive health issues with HIV-positive adolescents: Although the discussion of SRH issues between parents/ guardians and adolescents faces socio-cultural challenges, HIV/AIDS programs need to establish mechanisms for involving parents/guardians in discussing these issues with the adolescents. This should involve equipping parents/guardians with skills for handling adolescent SRH issues. There is also need to encourage HIVpositive young people to freely discuss the SRH issues not only with parents/ guardians but also with service providers/ counselors during counseling sessions given that some still find it difficult to talk to providers about these issues. 
- Programs need to strengthen support groups for HIV-positive adolescents and encourage them to join the groups: Support groups for people living with HIV are a source of peer and psychosocial support as well as life skills training. They are also potential avenues for channeling appropriate SRH information for the adolescents. However, the fact that many HIV-positive adolescents do not belong to the groups underscores the need for programs to strengthen these groups, especially for young people, and to encourage HIV-positive adolescent clients to join the groups.

- Programs also need to strengthen life skills training for HIV-positive adolescents: Many of the HIV-positive adolescents are vulnerable on account of the fact that they are young, they are living with a chronic illness, many have lost one or both parents, and the majority are out of school. In addition, most of those who are out of school did not go beyond primary education, which implies that prospects for career advancement are limited for many of them. HIV/AIDS programs therefore need to strengthen life skills training to enable them make informed choices, balance responsibility with sexual and reproductive desires, and to realize their potential in life. 


\section{References}

Bakeera-Kitaka, Sabrina, Nicolette Nabukeera-Barungi, Christiana Nöstlinger, Kekitiinwa Addy, and Robert Colebunders. 2008. "Sexual risk reduction needs of adolescents living with HIV in a clinical care setting." AIDS Care 20(4):426-433.

Birungi, Harriet, John F. Mugisha, Francis Obare, and Juliana Nyombi. 2009a. "Sexual behaviour and desires among adolescents perinatally infected with HIV in Uganda: Implications for programming." Journal of Adolescent Health 44(2):184-187.

Birungi, Harriet, Francis Obare, John Frank Mugisha, Humphres Evelia, and Juliana Nyombi. 2009b. "Preventive service needs of young people perinatally infected with HIV in Uganda." AIDS Care 21(6):725-731.

Birungi, Harriet, John Frank Mugisha, Juliana Nyombi, Francis Obare, Humphres Evelia, and Hannington Nyinkavu. 2008. "Sexual and reproductive health needs of adolescents perinatally infected with HIV in Uganda." FRONTIERS Final Report. Washington, DC: Population Council.

Birungi, Harriet, John Frank Mugisha, and Juliana Nyombi. 2007. "Sexuality of young people perinatally infected with HIV: A neglected element in HIV/AIDS programming in Uganda." Exchange on HIVI AIDS, Sexuality and Gender 3:7-9.

Hardon, Anita. 2005. "Confronting the HIV/AIDS epidemic in sub-Saharan Africa: Policy versus practice." International Social Science Journal 57(186):601-608.

National AIDS and STI Control Programme (NASCOP) [Ministry of Health, Kenya]. 2008. Kenya AIDS Indicator Survey 2007: Preliminary Report. Nairobi: NASCOP.

National AIDS and STI Control Programme (NASCOP) [Ministry of Health, Kenya]. 2005. "AIDS in Kenya: Trends, interventions and impact." $7^{\text {th }}$ ed. Nairobi: NASCOP. 
For more information, contact:

Project Director

APHIA II OR Project in Kenya

Population Council

General Accident Insurance House

Ralph Bunche Road

P.O. Box 1764300500

Nairobi, Kenya

Tel: 254202713480 - 3

Fax: 254202713479

www.popcouncil.org/projects/239_APHIAII.asp

\section{(P Population Council}

